\title{
Notch Signaling: Linking Embryonic Lung Development and Asthmatic Airway Remodeling
}

\author{
Musaddique Hussain, Chengyun Xu, Mashaal Ahmad, Youping Yang, Meiping Lu, Xiling Wu, \\ Lanfang Tang, and Ximei Wu
}

Department of Pharmacology and The Key Respiratory Drug Research Laboratory of China Food and Drug Administration, School of Medicine, Zhejiang University, Hangzhou City, China (M.H., C.X., M.A., Xim.W.); The Second People's Hospital of Wenling, Wenling City, Zhejiang Province, China (Y.Y.); and Department of Respiratory Medicine, the Affiliated Children Hospital, School of Medicine, Zhejiang University, Hangzhou City, China (M.L., Xil.W., L.T.)

Received August 14, 2017; accepted October 11, 2017

\section{ABSTRACT}

Lung development is mediated by assorted signaling proteins and orchestrated by complex mesenchymal-epithelial interactions. Notch signaling is an evolutionarily conserved cell-cell communication mechanism that exhibits a pivotal role in lung development. Notably, both aberrant expression and loss of regulation of Notch signaling are critically linked to the pathogenesis of various lung diseases, in particular, pulmonary fibrosis, lung cancer, pulmonary arterial hypertension, and asthmatic airway remodeling; implying that precise regulation of intensity and duration of Notch signaling is imperative for appropriate lung development. Moreover, evidence suggests that Notch signaling links embryonic lung development and asthmatic airway remodeling. Herein, we summarized allrecent advances associated with the mechanistic role of Notch signaling in lung development, consequences of aberrant expression or deletion of Notch signaling in linking early-impaired lung development and asthmatic airway remodeling, and all recently investigated potential therapeutic strategies to treat asthmatic airway remodeling.

\section{Introduction}

Lung development originates from the anterior foregut and is orchestrated by complex mesenchymal-epithelial interactions that coordinate the temporal and spatial expression of multiple regulatory factors for normal development (Morrisey and Hogan, 2010). Lung development occurs through sequential stages: embryonic stage (week 3-7 in humans; embryonic day (ED) 8.0-9.5 in mice), pseudoglandular stage (week 7-17; ED 9.5-16.5), canalicular stage (week 17-27; ED 16.5-17.5),

This work was supported by National Natural Science Foundation of China [81170016, 81170787, 81200022, 81200023, 81270067, 31571493, 81571928]; and Natural Science Foundation of Zhejiang Province [LY13H150002, LY12H16005]. All authors have no conflicts of interest.

https://doi.org/10.1124/mol.117.110254. saccular stage (week 27-36; ED 17.5 to postnatal day 5 (P5) in mice), and alveolar stage (week 36 to $\sim 7-10$ years in humans; P5 to P30 in mice) (Warburton et al., 2010; Schittny, 2017). Stages of lung development and expression of Notch signaling are depicted in Fig. 1. Later in gestation, epithelial progenitors are differentiated into basal cells, ciliated cells, goblet cells, and neuroendocrine cells (in proximodistal axis), submucosal glands consisting of mucous and serous cells (in the proximal region), and ciliated and Clara cells (in bronchioles that are distal to the trachea and bronchi). Alveoli, most distal part of the lungs, are layered with flattened type-I pneumocytes and cuboidal surfactant-producing type-II pneumocytes (Rawlins and Hogan, 2006). Airway epithelial cells are similar in mouse and human lung, but there are some differences. For instance, a pseudostratified epithelial layer including basal cells merely

ABBREVIATIONS: $\alpha$-SMA, smooth muscle $\alpha$-actin; ADAM, A disintegrin and metalloprotease; ANK, ankyrin repeats; bHLH, basic-helix-loop-helix; $\mathrm{CSL}, \mathrm{C}$ promoter-binding factor-1, also known as RBP-j $\kappa$ in mammals, suppressor of hairless, $\mathrm{Su}(\mathrm{H})$ in $D$. melanogaster, longevity-assurance gene-1, and LAG-1 in C. elegans; DAPT, tert-butyl (2S)-2-[[(2S)-2-[[2-(3,5-difluorophenyl)acetyl]amino]propanoyl]amino]-2-phenylacetate; DC, dendritic cells; DBZ, dibenzazepine; DII, Delta-like ligand; ECM, extracellular matrix; ED, embryonic days; EGF, epidermal growth factor-like repeats; OK EGFR, epidermal growth factor receptor; EMT, epithelial-mesenchymal transition; ERK, extracellular signal-regulated kinase; HD, heterodimerization domain; HES, Hairy and enhancer-of-split family of genes; HEY, Hairy and enhancer-of-split-related with a YRPW motif family of genes; IL, interleukin; Jag, Jagged (Serrate-family ligands); LNR, Lin-12-Notch repeats; MAML, Mastermind-like; NECD, Notch extracellular domain; NEXT, Notch extracellular truncated form; NICD, Notch intracellular domain; p, postnatal days; PDGF, platelet-derived growth factor; PNEC, pulmonary neuroendocrine cells; PEST, proline-glutamic acid-serine-threonine-rich motifs; RAM, RBP-j $\kappa$-associated molecule; RBP-j $\kappa$, recombination binding protein for immunoglobulin kappa J region; RSV, respiratory syncytial virus; SMRT, thyroid hormone receptor; TAD, transactivation domain; TMD, transmembrane domain; TN-C, tenascin-C; Treg, regulatory T-cell. 


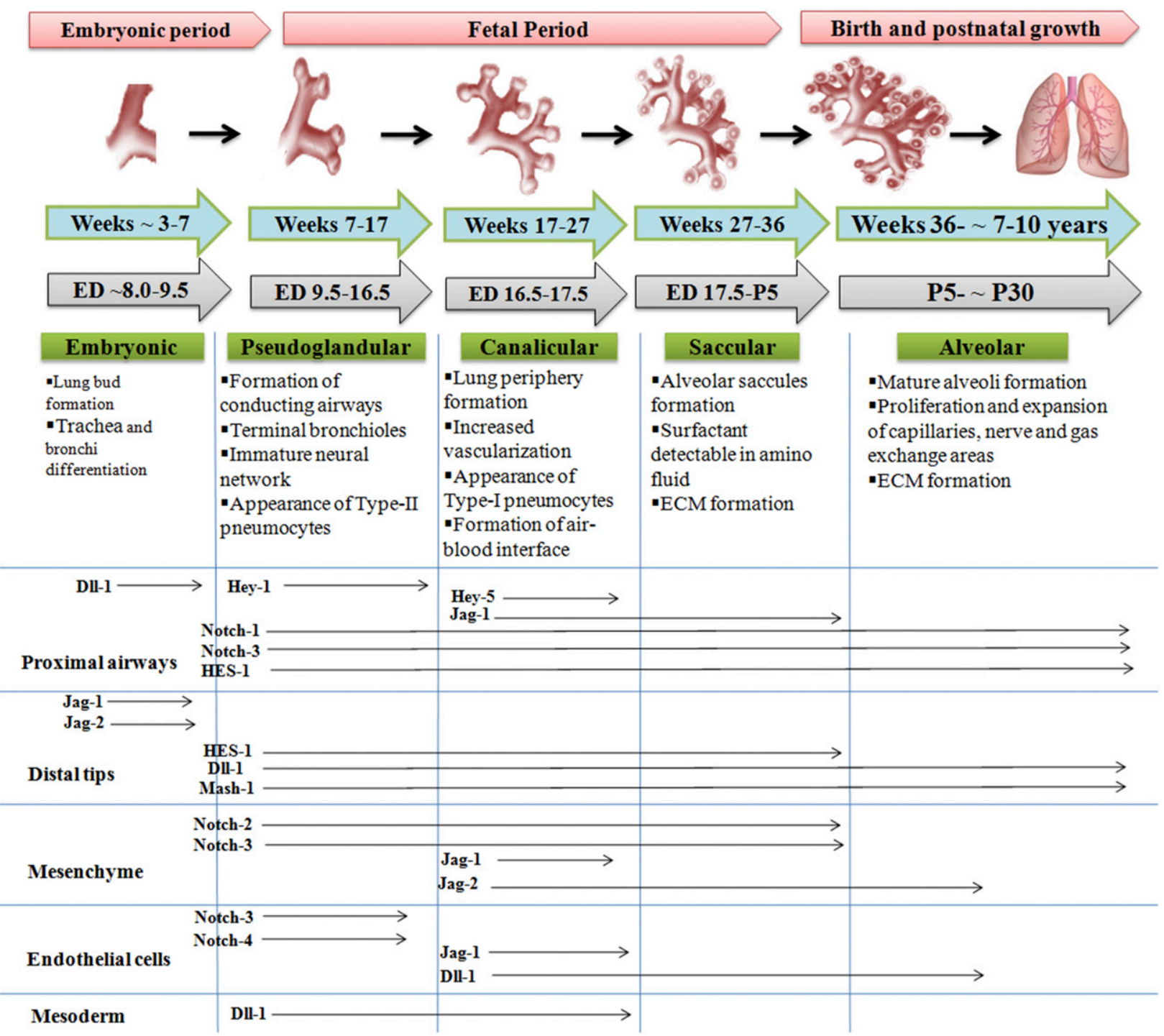

Fig. 1. Notch signaling and lung developmental stages in humans and mice. During embryonic stage (ED $\sim 8.0-9.5$ in mouse, $\sim 3-7$ weeks in human), lung development is initiated by the emergence of lung buds from foregut endoderm for the onset of lung specification. In the pseudoglandular stage (ED 9.5-16.5 in mouse, 7-17 weeks in human), numerous Notch ligands, receptors, and extracellular modulators are expressed within proximal-distal airways and surrounding mesenchyme that coordinate the proximal-distal patterning of branching morphogenesis. Most mesenchymal and epithelial cells start to form during this stage. In the canalicular stage (ED 16.5-17.5 in mouse, 17-27 weeks in human), Notch signaling regulates the balance of proliferation and differentiation of the distal airway epithelium and results in the appearance of AECI/II and formation of blood capillaries. In the saccular stage to alveolar stage (ED 17.5 to postnatal day 5 in mouse, 27-36 weeks in human), Notch signaling may organize the vascularization and alveolarization (sac-like structures), which is accompanied by the enlargement of lymphatic and capillary networks, and production of surfactant. In mouse, the alveolar stage starts postnatally (P5 to P30) whereas, in humans, it starts in utero (36 weeks to 7-10 years). Arrows represent the expression of Notch and its components at different stages of lung development.

originates in the main stem bronchus and trachea in mouse lung, whereas in human lung basal cells are distributed in the terminal bronchioles. Further, large numbers of Clara cells are thoroughly distributed in mouse lung, but in the human lung Clara cells are only found in the bronchiolar epithelium. Human lung contains extensive branches in the bronchial tree compared with mouse lung. Branching pattern is also different in both mouse and human lung (Metzger et al., 2008). Alveolar development starts from the saccular stage (ED 17.5) in mouse, whereas in human lung, alveolar expansion starts from the late canalicular stage ( $\sim 24$ weeks). Nevertheless, precisely coordinated signaling pathways regulate lung developmental processes, and disruptions of these signaling pathways could result in neonatal respiratory disorders, such as lung cancer, pulmonary fibrosis, chronic obstructive pulmonary disease, asthma, and airway remodeling.

Asthmatic airway remodeling, first described in 1922 (Huber and Koessler, 1922), is characterized by structural changes in the airway walls, such as thickened epithelium with mucous gland hypertrophy (mucus hypersecretion), thickened subepithelial basement membrane, deposition of extracellular matrix, fibrosis, angiogenesis, neovascularization, hyperplasia, and hypertrophy of airway smooth muscle cells and increased airway vascularity (Elias et al., 1999; James et al., 2012; Prakash, 2013; Fehrenbach et al., 2017). Asthmatic airway remodeling mediates the airway hyper-responsiveness, airway obstruction, pulmonary dysfunction, and infiltration of inflammatory cells, followed by 
chemokines, cytokines, and growth factors, under the influence of various signaling proteins, also known as morphogens, such as Wnt/ $\beta$-catenin, TGF- $\beta / \mathrm{BMP}$, fibroblast growth factor, epidermal growth factor, Sonic hedgehog, and Notch.

Notch, discovered in 1913 (Morgan, 1917), is an exceedingly conserved signaling system. Molecular mechanism of Notchsignaling activation and transduction is multifarious; however, fundamentally, after ligand binding, $\gamma$-secretase cleaves the released Notch intracellular domain (NICD), then this NICD translocates to the nucleus. The NICD interacts with the DNA-binding transcriptional repressor $(\mathrm{CBF}-1 / \mathrm{RBP}-\mathrm{j} \kappa)$ and converts it into a transcriptional activator complex (NICD-CBF-1/RBPj $\kappa-M A M L)$ that induces the transcription of target genes (Fig. 2). Notch regulates differentiation, development, proliferation, and apoptosis (McCright, 2003; Amsen et al., 2009; de la Pompa, 2009). Mutation in Notch components results in genetic disorders, such as spondylocostal dysostosis, T-cell acute lymphoblastic leukemia, alagille syndrome, cerebral dominant autosomal arteriopathy, and schizophrenia, as well as the commencement of multiple tumors (Mašek and Andersson, 2017). Moreover, aberrant expression of Notch has been implicated in the pathogenesis of lung diseases. In this review, we briefly discuss the molecular basis of Notch signaling, its role in lung development, and the consequences of aberrant expression of Notch signaling in the initiation and progression of asthmatic airway remodeling. Moreover, we emphasize relevant

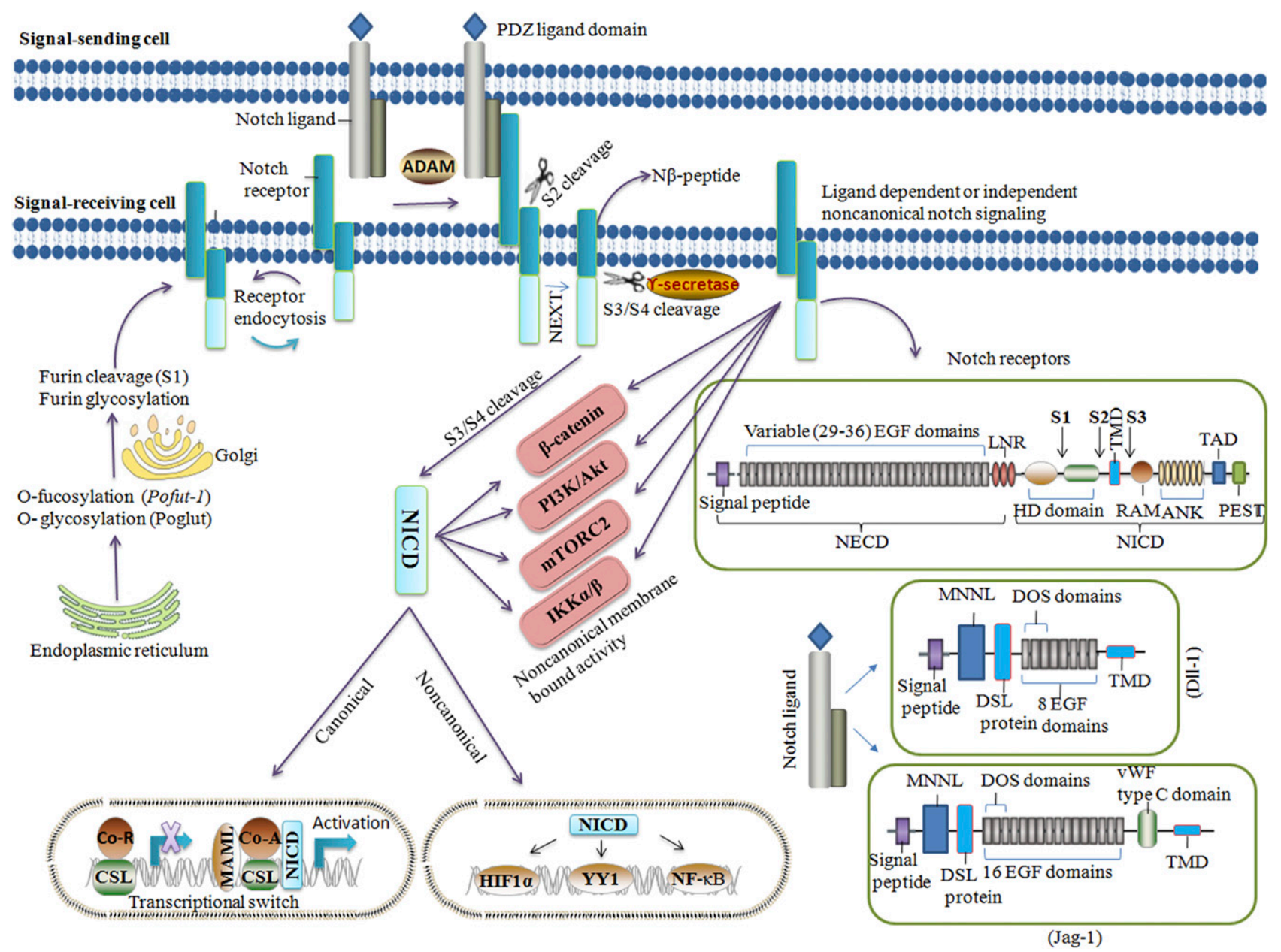

Fig. 2. Notch signaling (canonical and noncanonical), Notch receptor, and Notch ligand. Notch receptors and ligands are single-pass transmembrane receptors. Notch receptors contain 29-36 EGF-like repeats, followed by three LNRs while all Notch ligands, except for Dll-3, contain variable numbers of EGF-like repeats, followed by DOS domain and DSL domains. The newly translated Notch receptor protein is glycosylated to mature receptor after proteolytic cleavage by furin at site 1 (S1) and then targeted to the cell surface as a heterodimer. Membrane-bound Notch receptor is activated by binding with ligand on a neighboring cell, which results in S2 cleavage at site 2 to generate the membrane-anchored NEXT fragment, by ADAM; followed by S3/S4 cleavage at site 3 (S3) to site 4 (S4) to release the stable form of NICD and N $\beta$ peptide with $\gamma$-secretase. The NICD contains the RAM domain, two nuclear localization signals, six ANK repeats, and a PEST sequence that regulates NICD degradation. Released NICD then translocates to the nucleus where it associates with the DNA-binding protein CSL. In the absence of NICD, CSL may associate with ubiquitous corepressor (Co-R) proteins and histone deacetylases to repress transcription. In the presence of NICD, allosteric changes may occur in CSL which displaces the transcriptional repressors, then MAML recognizes the NICD/CSL interface to recruit additional coactivators (Co-A) for the transcription. Noncanonical Notch signaling may occur via the membrane-bound, uncleaved Notch receptor or via the NICD. Noncanonical Notch signaling is independent of CSL and allows for interaction with $\mathrm{PI} 3 \mathrm{~K} / \mathrm{AKT} / \mathrm{mTORC} 2, \mathrm{Wnt} / \beta$-catenin, IKK $\alpha / \beta, \mathrm{NF} \kappa \mathrm{B}, \mathrm{YY} 1$, and HIF1 $\alpha$ pathways at the cytoplasmic and/or nuclear level. DOS, Delta and OSM-11-like proteins; DSL, Delta-Serrate-LAG-2; EDF, epidermal growth factor; HIF-1 $\alpha$, hypoxia-inducible factor-1 $\alpha$; LNR, Lin-12-Notch repeats; MNNL, N-terminal domain of Notch ligands; NF- $\mathrm{B}$, nuclear factor kappa-light-chain-enhancer of activated B cells; PI3K, phosphoinositide-3-kinase; vWF, von Willebrand factor; YY1, Yin and Yang 1. 
potential therapeutic targets to regulate/inhibit the Notch signaling to facilitate the appropriate treatment of asthmatic airway remodeling.

\section{Regulation of Notch Signaling}

The taxonomy and structural features of the molecules involved in and the commencement mechanism of Notch receptors are different among Drosophila melanogaster, Caenorhabditis elegans, and mammals. For this reason we discuss the Notch signaling pathway in mammalian cells. Four Notch receptors (Notch-1, Notch-2, Notch-3, and Notch-4) and five major ligands [three Delta-family ligands (Delta-like ligands Dll-1, Dll-3, and Dll-4) and two Serrate-family ligands (Jagged Jag-1 and Jag-2) ] have been recognized in mammals (Kopan and Ilagan, 2009; Guruharsha et al., 2012) (Table 1). Although all Notch receptors exhibit the same structures, they show considerable differences in the protein domains. Notch receptors are synthesized as large precursors in the endoplasmic reticulum, travel to the plasma membrane through the exocytic pathway, and then undergo various post-translational alterations. During the maturation process, in the endoplasmic reticulum, the sequence of signals located at the N-terminus is cleaved off, and the extracellular domain of Notch is subjected to modification mediated by glycosyltransferases (Rana and Haltiwanger, 2011). For instance, O-fucosylation by protein $O$-fucosyltransferase 1 (Pofut-1) and consequent elongation of chain with O-linked $\beta$-D- $N$-acetylglucosamine (O-GlcNAc) by fringe genes (radical, manic, and lunatic fringe) regulate the ligand specificity in Golgi complex (Bruckner et al., 2000; Okajima et al., 2003; Kovall et al., 2017). Moreover, $\mathrm{O}$-glucosylation by protein-O-glucosyltransferase (Poglut) in the endoplasmic reticulum is essential for activation of the receptor (Acar et al., 2008), and further elongation of chain with $O$-xylose negatively regulates Notch receptor (Lee et al., 2013). In Golgi complex, Notch extracellular domain undergoes its first proteolytic cleavage by a Furin-like proprotein convertase at site S1 (Logeat et al., 1998), although S1 cleavage is not necessary for signal activation but facilitates exocytosis (Gordon et al., 2009) (Fig. 2). After cleavage, Notch receptors are presented as heterodimers of a large, modular, N-terminal portion of the plasma membrane, which is exposed to extracellular spaces known as Notch extracellular domain (NECD). NECD is noncovalently attached to the C-terminal part of the multidomain intracellular portion that contains transcriptional activity, referred to as NICD; hence, Notch receptors contain large extracellular and small intracellular domains. The extracellular domains of Notch-1 and Notch-2 include 36 epidermal growth factor-like repeats (EGF) each, whereas those of Notch3 and Notch-4 contain 34 and 29, respectively (Radtke and Raj, 2003). These domains bind to calcium ions and provide a necessary function in receptor-ligand binding (Cordle et al., 2008) as well as in signaling efficacy (Raya et al., 2004). Generally, NECD is acknowledged as inhibitory, because EGF-like repeats are followed by a negative regulatory region, which comprises three cysteine-rich Lin-12-Notch repeats (LNR) and a Notch heterodimerization region that perform a crucial role in inhibiting inappropriate Notch activation

TABLE 1

Notch pathway components in vertebrates and mammals

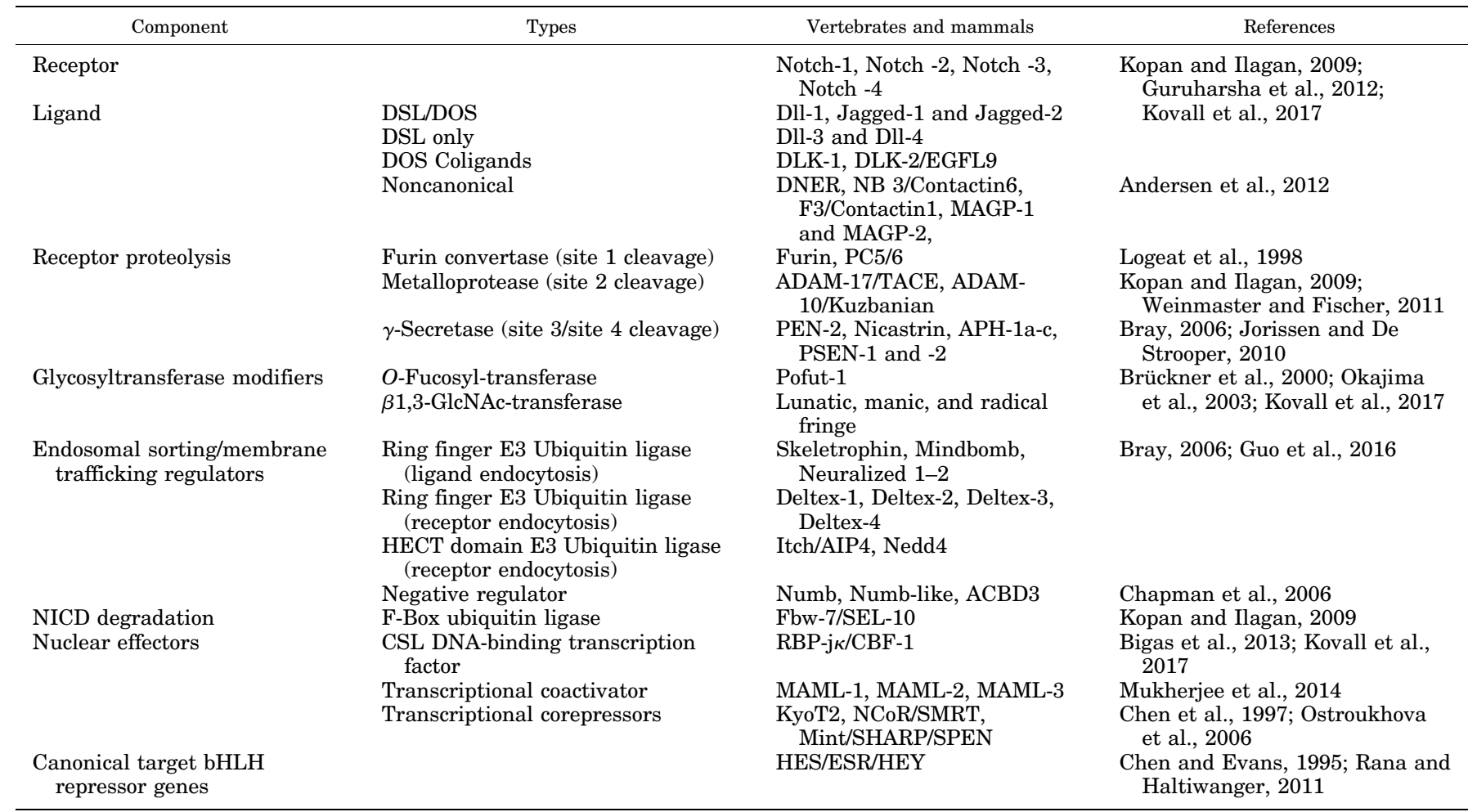

AP2, adaptor protein-2; APH-1, anterior pharynx-defective 1; CSL, CBF1/RBP-jk/Su(H)/Lag-1; DOS, Delta and OSM-11-like proteins motif; DSL, Delta/Serrate/LAG-2 motif; E3, ubiquitin ligase; NICD, Notch intracellular domain PEN, Presenilin enhancer; PSEN, Presenilin; SMRT, a silencing mediator for retinoid or thyroid hormone receptors. 
(Malecki et al., 2006; Kopan and Ilagan, 2009) as well as modulating the communications between NECD and NICD (Greenwald, 1994). Notch intracellular domain consists of the recombination binding protein for immunoglobulin kappa

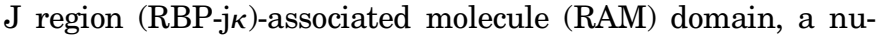
clear localization signal, seven ankyrins (ANK) repeats, a transactivation domain (TAD), and a degradation domain [glutamine-rich repeat/proline-glutamic acid-serine-threoninerich motifs (PEST) to regulate the stability (Bigas et al., 2013)] (Fig. 2). Classic TAD is present in Notch-1(strong TAD) and Notch-2 (weak TAD) and is not present in Notch-4 (Ong et al., 2006). Notch-3 contains potent but specific TAD for activation of the Hairy and enhancer-of-split (HES)-5 promoter. It has been revealed that RAM domains exhibit a crucial role in NICD and $\mathrm{RBP}-\mathrm{j} \kappa$ interaction, whereas ankyrin repeats are also critical for transcriptional activation complex formation and recruitment of Mastermind-like (MAML)-1 (Nam et al., 2006). In addition, NICD contains nuclear localization sequences and target sites for ubiquitination (Fryer et al., 2004), phosphorylation, and hydroxylation (Ramain et al., 2001). A list of proteins that interact with NICD by phosphorylation, ubiquitination, and hydroxylation are described in Table 2.

In mammals, Notch ligands are type-1 transmembrane proteins with a relatively small intracellular domain and a

TABLE 2

Various proteins interacting with NICD

\begin{tabular}{|c|c|c|}
\hline Symbol & Protein & Interface with NICD \\
\hline \multicolumn{3}{|l|}{$\begin{array}{l}\text { Regulation of NICD by } \\
\text { phosphorylation }\end{array}$} \\
\hline GSK3 $\beta$ & Glycogen synthase kinase 3 & $\begin{array}{l}\text { Phosphorylates Notch, which can lead to degradation or } \\
\text { stabilization }\end{array}$ \\
\hline CycC & Cyclin C & $\begin{array}{l}\text { Target NICD along with CDk8 for phosphorylation that } \\
\text { subsequently acts as substrate for ubiquitylation and } \\
\text { degradation }\end{array}$ \\
\hline CDK8 & Cyclin-dependent kinase 8 & $\begin{array}{l}\text { Phosphorylates NICD with CycC that subsequently acts } \\
\text { as substrate for ubiquitylation and degradation }\end{array}$ \\
\hline G-CSF & Granulocyte colony-stimulating factor & $\begin{array}{l}\text { Phosphorylation of NICD that subsequently leads to its } \\
\text { inactivation }\end{array}$ \\
\hline \multicolumn{3}{|l|}{$\begin{array}{l}\text { Regulation of NICD by } \\
\text { ubiquitylation }\end{array}$} \\
\hline Fbxw7/Cdc4 & F-box/WD-repeat protein 7 & Ubiquitylates the NICD leading to its degradation \\
\hline Numb & Numb homolog & $\begin{array}{l}\text { Suppresses Notch signaling by recruiting E3 ubiquitin } \\
\text { ligases to ubiquitylate Notch }\end{array}$ \\
\hline Dtx1-4 & Deltex $1-4$ & $\begin{array}{l}\text { Controls Notch ubiquitylation, processing, and } \\
\text { internalization }\end{array}$ \\
\hline Itch & Itchy, E3 ubiquitin protein ligase & Promotes ubiquitylation of NICD \\
\hline \multicolumn{3}{|l|}{$\begin{array}{l}\text { Regulation of NICD by } \\
\text { hydroxylation }\end{array}$} \\
\hline FIH & Factor inhibiting HIF $1 \alpha$ & Hydroxylates the Notch and represses Notch \\
\hline $\operatorname{HIF} 1 \alpha$ & Hypoxia-inducible factor 1 , alpha subunit & $\begin{array}{l}\text { Stabilizes the NICD and synergizes with it in } \\
\text { transcription of Notch target genes }\end{array}$ \\
\hline \multicolumn{3}{|l|}{$\begin{array}{l}\text { Miscellaneous proteins } \\
\text { interacting with NICD }\end{array}$} \\
\hline Axin & Axin & $\begin{array}{l}\text { Synergies with NICD to regulate the stability of } \\
\beta \text {-catenin and controls the trafficking of NICD in } \\
\text { association with adenomatous polyposis coli }\end{array}$ \\
\hline Apc & Adenomatous polyposis coli & Control the trafficking of Notch \\
\hline $\mathrm{CSL} / \mathrm{RBP}-\mathrm{j} \kappa$ & $\mathrm{CBF} 1, \mathrm{Su}(\mathrm{H})$ and LAG-1/RBP-j $\kappa$ & Key canonical transcriptional cofactor for NICD \\
\hline Ctnnb1 & $\beta$-catenin & Synergies with NICD/CSL on Notch target gene \\
\hline Dab & Disabeled & $\begin{array}{l}\text { Acts as link to Abelson tyrosine kinase (Abl) protein in } \\
\text { noncanonical Notch axon guidance }\end{array}$ \\
\hline $\mathrm{Dvl} / \mathrm{Dsh}$ & Dishevelled & $\begin{array}{l}\text { Dishevelled regulates ligand-dependent Notch } \\
\text { trafficking and inhibits canonical Notch signaling }\end{array}$ \\
\hline MAML-1/2 & Master mind-like-1/2 & Coactivator of NICD/CSL \\
\hline $\mathrm{NF}-\kappa \mathrm{B}$ & $\begin{array}{l}\text { Nuclear factor of kappa light polypeptide } \\
\text { gene enhancer in B-cells } 1\end{array}$ & $\begin{array}{l}\text { NICD blocks NF- } \kappa \text { B transcription of NF- } \kappa \text { B target genes } \\
\text { through binding to p50/cRel }\end{array}$ \\
\hline Nrarp & Notch-regulated ankyrin repeat protein & Nrarp binds and inhibits the NICD/CSL \\
\hline $\mathrm{p} 73 \alpha(\mathrm{TA})$ & $\begin{array}{l}\text { Tumor protein p73 alpha (transactivating } \\
\text { form) }\end{array}$ & $\begin{array}{l}\text { Binds NICD and inhibits the NICD/CSL-mediated } \\
\text { transcription }\end{array}$ \\
\hline RITA/C12ORF52 & $\mathrm{RBP}-\mathrm{j} \kappa$ interacting and tubulin associated & $\begin{array}{l}\text { Shuttles NICD between the nucleus and cytoplasm on } \\
\text { tubulin networks }\end{array}$ \\
\hline SMAD & Smad family members & $\begin{array}{l}\text { Smads augment Notch signaling, Notch fine-tunes } \\
\text { signaling via Smads }\end{array}$ \\
\hline SNW1/SKIP/NCOA-62 & $\begin{array}{l}\text { SNW domain-containing protein 1/Ski- } \\
\text { interacting protein/Nuclear receptor } \\
\text { coactivator NCoA- } 62\end{array}$ & $\begin{array}{l}\text { Can bind both NICD and corepressor SMRT, but these } \\
\text { are mutually exclusive; forms multimers with NICD } \\
\text { and MAML, which then associates with CSL to } \\
\text { activate transcription }\end{array}$ \\
\hline Tacc3 & $\begin{array}{l}\text { Transforming, acidic coiled-coil } \\
\quad \text { containing protein } 3\end{array}$ & $\begin{array}{l}\text { Binds NICD and blocks transcription from Notch target } \\
\text { promoters; can be reversed by overexpression of CSL }\end{array}$ \\
\hline Trio & $\begin{array}{l}\text { Triple functional domain (PTPRF } \\
\text { interacting) }\end{array}$ & $\begin{array}{l}\text { A guanine nucleotide exchange factor (GEF) for Rho } \\
\text { GTPases that acts as link to Abelson tyrosine kinase } \\
\text { (Abl) proteins in noncanonical Notch axon guidance }\end{array}$ \\
\hline
\end{tabular}

CDK, cyclin-dependent kinase; E3, ubiquitin ligase; HIF, hypoxia-inducible factor; NF- $\kappa$ B, nuclear factor kappa-light-chain-enhancer of activated B cells; RITA, RBP-j interacting and tubulin-associated; SKIP, Ski-interacting protein; SMRT, a silencing mediator for retinoid or thyroid hormone receptors. 
large extracellular domain. Synthesis, trafficking, and exocytosis of the Notch ligands are the same as for Notch Receptors. In Notch ligands, three interconnected structural patterns are described: EGF-like repeats (variable numbers), Delta and OSM-11-like proteins (DOS) domain (a specialized tandem EGF-repeat) and Delta-Serrate-LAG-2 (DSL) domain (a cryptic EGF-like repeat); DOS and DSL domains, both, are implicated in receptor binding (Kopan and Ilagan, 2009) (Fig. 2). Nevertheless, because of the presence or absence of a cysteine-rich domain, Notch ligands can be classified into the Delta-like group or the Jagged/Serrate group (D'Souza et al., 2008). Notch signaling pathway components are depicted in Table 1.

Canonical Notch Signaling. Importantly, Notch signaling is initiated upon interaction of signal-dispatching (Notch ligand-containing) and signal-receiving (Notch receptorcontaining) cells, the result of which is initiation of a transendocytosis process and binding of ligands to the extracellular domain of Notch receptor.

For ligand endocytosis, an E3 ubiquitin ligase, Mindbomb-1, performs the critical role in the mono-ubiquitination of the intracellular domains of ligands in mammals (Koo et al., 2007), and Notch signal activation fails in the absence of ligand ubiquitination. After ligand binding and endocytosis, the ligand induces a conformational change on the extracellular domain of Notch, exposing the S2 proteolytic cleavage site operated by A disintegrin and metalloproteinase (ADAM) at site S2 (Weinmaster and Fischer, 2011) (Fig. 2). S2 cleavage is a key step for Notch activation, but some uncertainties still exist regarding enzymes responsible for cleavage. Indeed, ADAM10 is generally considered to be the protease that is responsible for ligand-inducible cleavage, whereas ADAM17 is responsible for ligand-independent cleavage (Kopan and Ilagan, 2009). However, cleaved S2 (second cleavage) remains entrenched in the membrane and is known as Notch extracellular truncated form (NEXT). NEXT acts as a substrate of the $\gamma$-secretase complex, $\mathrm{n}$ intramembrane protease (Jorissen and De Strooper, 2010). In turn, Notch exposes the S3 cleavage site to $\gamma$-secretase complex, which is composed of Presenilin 1, anterior pharynx-defective 1 , Presenilin enhancer 2, and Nicastrin, undergoes S3 cleavage (third cleavage), and eventually releases the NICD from the membrane (Bray, 2006) (Table 1). The exact subcellular location of $\gamma$-secretase cleavage is still controversial, i.e., $\gamma$-secretase cleavage occurs at multiple sites within the transmembrane domain; however, most probably occurs at the plasma membrane and in the endocytic vesicles (Yamamoto et al., 2010). The pharmacological effects of Notch signaling can be minimized by targeting the S3 cleavage via $\gamma$-secretase inhibitors. NICD then enters the nucleus and interacts with DNA-binding protein, to accumulate a transcriptional complex comprising NICD, CSL [C promoter-binding factor-1 (CBF-1) also known as $\mathrm{RBP}-\mathrm{j} \kappa$ in mammals; suppressor of hairless, $\mathrm{Su}(\mathrm{H})$ in D. melanogaster; longevity-assurance gene-1, LA $\mathrm{G}-1$, in C. elegans], and coactivator of Mastermind (MAML-1, MAML2, MAML-3 in mammals and MAM in Drosophila) through ANK and RAM domains of NICD and converts it into transcriptional activator to induce transcription of target genes. In the absence of Notch, CSL, mainly CBF-1/RBP-j $\kappa$ in mammals, recruits transcriptional corepressors such as Ski-interacting protein, Hairless $(\mathrm{H})$, C-terminal-binding protein-1, SPEN [also known as SHARP/MINT (SMRT/HDAC-1-associated repressor protein, SHARP, in human/MINT in mouse homologs) and Msx2-interacting nuclear target], RBP-j $\kappa$ interacting and tubulin-associated protein, Groucho to recruit histone deacetylases, a silencing mediator for retinoid or thyroid hormone receptors (SMRT), and further repressive cofactors to depress the expression of Notch target genes (Chen and Evans, 1995; Oswald et al., 2005). In the presence of NICD, SKIP collaborates with ankyrin repeat domain of NICD to assist NICD function by dissociating the repressor complex (Zhou et al., 2000) and recruits the CBF-1 transcriptional coactivators, like chromatin-remodeling complexes and histone acetyltransferases (Kurooka and Honjo, 2000 ), to create a short-lived transcriptional activation complex, NICD-CBF-1/RBP-j $\kappa-\mathrm{MAML}$, which then activates a downstream target gene via the addition of an extra coactivator, such as histone acetyltransferase p300 (Fryer et al., 2002; Wallberg et al., 2002) (Fig. 2). The best-known Notch targets are the components of basic-helix-loop-helix (bHLH) family genes such as Hairy and enhancer-of-split family of genes (HES-1, -3, -5 and -7) and Hairy and enhancer-of-split-related with a YRPW motif (HEY) family of genes (HEY-1, HEY-2 and HEY-L) (Ranganathan et al., 2011; Chen et al., 2014). These components act as transcription repressors either by direct binding to the $\mathrm{E}$ and $\mathrm{N}$ regions, or attaching corepressor (Groucho), or by a unique mechanism still mysterious but independent of direct protein binding. In addition to HES and HEY family genes, CyclinD1 (cell-cycle promoter), c-MyC (proliferation-related gene), Bcl-2 (anti-apoptotic gene), the gene for HER-2, Deltex-1, p21Cip1/Waf1, Notch-regulated ankyrin repeat protein (Nrarp), and the pre-T-cell receptor gene have also been described as Notch target genes (Takebe et al., 2014; Wakabayashi et al., 2015). Mostly Notch-mediated processes need a transient activation, but a few procedures require prolonged activation. Hence, continuous signal activation is controlled at a regulation point that shuts off the Notch signaling via phosphorylation of NICD within the PEST domain by kinases such as cyclin-dependent kinase-8 (CDK8) (Fryer et al., 2004) and is targeted for polyubiquitination via E3 ubiquitin ligases such as SEL10/FBXW7, which results in proteasome-mediated degradation and termination of Notch signaling and resets the cells for the next round of signaling (Guo et al., 2016; Kovall et al., 2017). It yet needs to be recognized whether CDK8 and FBXW7 are common mediators of NICD degradation, because some other kinases and E3 ubiquitin ligases are considered to be contributors to NICD regulation in context-dependent circumstances. Additionally, Notch activity can also be determined by the ubiquitylation status of the receptor. Thereby phosphatases, ubiquitin ligases, and kinases remain to be identified and characterized. The proteins that interact with NICD and influence the output of signaling pathway are described in Table 2.

Non-canonical Notch Signaling. Several recent studies have revealed the existence of numerous modes of Notch signaling, in addition to canonical Notch signaling, commonly referred as noncanonical Notch signaling. Noncanonical Notch signaling is related to other, different transcription factors, such as hypoxia-inducible factor- $1 \alpha, \beta$-catenin, estrogen receptor $(\mathrm{ER} \alpha)$, Yin and Yang 1, and nuclear factor kappalight-chain-enhancer of activated B cells (NF- $\kappa$ B), instead of CSL (CBF1, suppressor of hairless, and Lag-1) transcription 
factor (Fig. 2). Interestingly, canonical Notch signaling is associated with various normal cellular processes such as early development of embryo, lungs, and other physiologic processes, whereas noncanonical Notch signaling is mainly concerned with potentially pathologic conditions like cancer and activation of the immune system. Hence, blockade of noncanonical Notch signaling may possibly establish new opportunities to inhibit pathologic conditions without harming normal physiologic processes; A more detailed description of noncanonical Notch signaling pathway can be found elsewhere (Andersen et al., 2012) and is beyond our topic of discussion.

\section{Regulatory Role of Notch Signaling in Fetal Lung Development}

Early Proximodistal Cell Fates. It is challenging to evaluate the participation of Notch signaling in normal lung development owing to the complexity of Notch receptor/ligand interactions, but experimental data has revealed that Notch signaling performs the crucial role in regulating the patterning and proximodistal cell fate in the early lung development (Tsao et al., 2008). Genetic ablation of RBP-jk or Pofut-1from developing epithelium or mesenchyme demonstrated the substantial differentiation defect in proximal airways, including complete ablation of the Club-cell secretory lineage and overpopulation of ciliated cells and neuroendocrine cells; the same defects were also found in the DAPT ( $\gamma$-secretase inhibitor)-treated proximal airways explants (Tsao et al., 2009; Morimoto et al., 2010).

In addition, expression patterns of Notch receptors, ligands, and other constituents (ED 11.5 to maturity) also suggest the participation of Notch signaling in regulating proximodistal cell fates. For instance, Notch-1 is persistently expressed in the distal lung endoderm, Notch-2 and Notch-3 both are articulated in fetal lung mesenchyme, and Notch-4 is endothelial-specific, although Notch-3 can be articulated in mesenchyme and endothelial cells of the airway (Post et al., 2000). During budding, Dll-1 is restricted to the proximal area, whereas Jag-1 and Jag-2 are found in the distal region (Kong et al., 2004). Jag-1 is highly expressed in proximal airways (ED 16.5) (Zhang et al., 2013a) and Jag-2 expression (ED 13) is observed in peripheral lung mesenchyme (Post et al., 2000). Dll-1is first expressed in the secondary bronchi (ED 13.5) and gradually rises within bronchioles and branch points until birth (Post et al., 2000). Postnatally, Dll-1 expression has been identified in endothelial cell lining the lung vasculature throughout the lung tissue (Beckers et al., 1999; Post et al., 2000). Hence, Dll-1 is well located to relate a subset of Notch proteins expressed in SPNC cells/Club-like cell that surrounds neuroepithelial bodies (Morimoto et al., 2010; Guha et al., 2014). Dll-4 expression is restricted to endothelial cells in the lung (Yoneya et al., 2001). Further, HES-1 expression starts from the early pseudoglandular stage (ED 12) and gradually rises until birth, and it can also be promptly detected in nonendocrine airway epithelial cells in the fetal lung (Ito et al., 2000). Predominantly, HES-1reactive cells are differentiated into Club cells in distal airway epithelium (ED 17 at low levels), and remnants continue up to fetal lung development (Hackett et al., 1992). HEY-1 is notably expressed in developing lung, but HEY-2 expression is low (Steidl et al., 2000). HEY-L is expressed in lung vasculature (Leimeister et al., 2000).
Differentiation of Pseudostratified Epithelium. Notch signaling regulates the differentiation of pseudostratified epithelial layer, including basal cells, mainly toward secretory lineages in the airway (Rock et al., 2011), whereas genetic and pharmacological inhibition of Notch-3 leads to the aberrant expansion of basal cells and altered pseudostratification (Mori et al., 2015). Further, Notch is required to maintain the Club cells (Pardo-Saganta et al., 2015), although conditional deletion of HES-1 or RBP-jк or Pofut-1 produced a remarkable elevation in ciliated cell count and attenuated Club-cell count; in fact, in the dearth of such signaling, cells are generally intended to turn into ciliated cells through a default program (Tsao et al., 2009; Morimoto et al., 2010). Transgenic misexpression of the Notch-1 intracellular domain in distal epithelial cells demonstrated ectopic expression of Club cells (Guseh et al., 2009). Furthermore, Jag-1 actively participates in controlling Notch-dependent differentiation of Club cells during lung development, because spatial-temporal deletion of Jag-1 in the airway epithelium caused aberrant cell-fate specification, with ciliated cells in excess at the expense of Club cells, a phenotype correlated with downregulation of HES-1 (Zhang et al., 2013a). Moreover, mouse trachea and human airway basal cells both undergo self-renewal and generate ciliated and Club-cell lineages (Engelhardt et al., 1995; Rock et al., 2009). In the Scgb1a1-CreER knockin mouse, the majority of Club cells in bronchioles undergo both selfrenewal and generate ciliated cells while in the trachea; Club cells generate ciliated cells but do not undergo self-renewal (Rawlins et al., 2009). Taken together, differentiation of airway epithelium into the secretory, ciliated, Club, and neuroendocrine cell types in the developing and adult murine lung is regulated by Notch signaling, but little human data are available beyond reports that Notch-1 and Notch-3 pathways regulate the differentiation of basal cells into ciliated and secretory cells (Gomi et al., 2015) via Jag-1 mediation (Gomi et al., 2016).

Pulmonary Neuroendocrine Cell Differentiation. Pulmonary neuroendocrine cells (PNEC) differentiation is regulated by Notch signaling (Ito et al., 2000). HES-1 and Mash-1 are expressed in nonneuroendocrine cells and pulmonary neuroendocrine cells (and neuroepithelial bodies in lungs), respectively. However, analyses of both Mash-1 and HES-1 knockout mice showed a significant correlation between Notch/Notch-ligand pathways and the regulation of bHLH proteins in the cell-fate decision in developing lung. An elevated level of Mash-1 mRNA and pulmonary neuroendocrine cells has been observed in HES-1-deficient mice, whereas lack of pulmonary neuroendocrine cells has been noticed in Mash-1-deficient mice (Borges et al., 1997; Ito et al., 2000). Nevertheless, the exclusive interaction between HES-1 and Mash-1 is the consequence of direct suppression of Mash-1 promoter by HES-1, and the ability of Notch-1, HES-1independent, to promote degradation of Mash-1 (Chen et al., 1997; Sriuranpong et al., 2002). Hence, Notch-1 might control the expression of HES-1and inhibit the fate of pulmonary neuroendocrine cells, in view of the fact that antisense oligonucleotides of Notch-1 promoted the differentiation of PNEC, and transgenic expression of Notch-1 intracellular domain blocks the differentiation of PNEC (Kong et al., 2004; Shan et al., 2007). Expression of the Dll-1 in neuroendocrine cells, and Notch-1, -2 , and -3 in nonneuroendocrine cells further authenticated this model (Xu et al., 2010). Consequently, Dll-1-mediated activation of Notch could significantly encourage the expression of HES- 1 and suppression 
of neuroendocrine differentiation via lateral inhibition (Noguchi et al., 2015). Importantly, Jag-1deletion resulted in an increased number of PNEC (Zhang et al., 2013a). On the other hand, conditional removal of $R B P-j \kappa$ in lung endoderm has no robust influence on the number of PNECs or expression of HES-1. Moreover, an involvement of noncanonical Notch signaling in neuroendocrine cell-fate selection is determined by Notch-1, $-2,-3$ triple knockouts, which results in a massive expansion of neuroepithelial bodies (Morimoto et al., 2010; Morimoto et al., 2012). Hence, under normal physiologic conditions, most probably a noncanonical pathway might compel inhibition of pulmonary neuroendocrine cells fate and expression of HES-1. However, such mechanisms could use signaling different from JAK, Alk5, FGFR, or extracellular signal-regulated kinase (ERK) kinases (Niwa et al., 2007; Yoshiura et al., 2007; Xing et al., 2010).

Pulmonary Goblet Cell Fate. Notch signaling also regulates the fate of pulmonary goblet cells, but it is complicated to evaluate the precise physiologic participation of Notch signaling in this context owing to the paucity of goblet cells in the murine airway epithelium. It has been reported that Dll-4 augmented the number of Muc5AC goblet cells in both human airway cell cultures and murine tracheal explants studies (Guseh et al., 2009). Interestingly, mice with conditional inactivation of $R B P-j \kappa$ or Pofut-1 via Tgfb3-Cre could survive to adulthood with aberrant airway phenotype characterized by obvious goblet cell metaplasia, increased ciliated cell numbers, and attenuated Club-cell count (Tsao et al., 2011). Moreover, goblet-cell metaplasia is observed in adult Jag-1-deleted mice lungs, indicating that Jag-1 contributes to repression of mucin production and goblet cell fate, accompanied by downregulation of Dll-1, HES-1, and HES-5 (Zhang et al., 2013a). Recently, it has been demonstrating that Notch signaling, particularly Notch-2, directly promoted the pulmonary goblet cells, whereas anti-Notch-2 antibodies prevented the interleukin (IL)-13, as well as allergen-driven goblet cell metaplasia (Danahay et al., 2015; Lafkas et al., 2015).

Alveolar and Microvasculature Development. Alveolar development takes place because of coordinated proceedings of endothelium, epithelium, and mesenchymal stroma in the distal lung. Notch signaling exhibits a pivotal role in the cell differentiation and cell-fate specification in the vascular and parenchymal compartments to coordinate the alveolar and microvasculature development. Constitutive expression of Notch in the peripheral (Dang et al., 2003) and distal (Guseh et al., 2009) lung epithelium in mice caused perinatal lethality owing to aberration and/or inhibition of differentiation of alveolar cells into type-I and type-II cells. Additionally, dilated cysts, which appear on proximal airway epithelium, were lacking some markers, particularly SP-C, keratin-5, $\beta$-tubulin, transformation-related protein 63 (p63), Club-cell 10-kDa protein (CC10), but not all markers (Guseh et al., 2009). In contrast, conditional deletion of $R B P-j \kappa$ or Pofut-1in lung epithelium exhibited no negative impact on the differentiation of alveolar epithelial cells and formation of alveolar saccules (Tsao et al., 2009; Morimoto et al., 2010). Interestingly, failure of alveolar septation and defective alveolar development have been reported in Notch- $2^{+/-}$ Notch- $3^{-l-}$-compound mutant (lfng) knockout mice owing to flawed differentiation and recruitment of myofibroblast cells rather than alveolar epithelial cells, whereas conditional deletion of RBP-j $\kappa$ (ED 14.5-18.5) impaired the myofibroblast differentiation without affecting the alveolar epithelial cells (Xu et al., 2010).

Notch-deficient mice, such as Jag-1 or lfng mutants, that survived postnatally helped the investigation of Notchmediated events in alveolar development. Conditional deletion of Jag-1 in lung epithelium that disrupted alveolar septation showed no effect on differentiation and maturation of alveolar epithelial cells (Zhang et al., 2013a). Moreover, overexpression of $l$ fng in distal lung epithelium did not affect the spatial or temporal expression of HES-1 and Mash-1, nor the expression of proximal ciliated, nonciliated, distal epithelial cell, and mesenchymal cell markers (von Willebrand factor, $\alpha$-SMA, PECAM-1) (van Tuyl et al., 2005). However, Tsao et al. (2016) used the epithelial Notch-2-null mice to determine that epithelial Notch signaling regulates alveologenesis by triggering the paracrine activation of platelet-derived growth factor (PDGF)-receptor- $\alpha$ signaling in alveolar myofibroblast progenitors, whereas overexpression of stimulated Notch-2 reversed the negative effect of Notch inhibition.

Of note, infiltration of growing microvasculature into emerging alveolar walls is necessary for talveolar development. This infiltration event is strongly coordinated with alveolar epithelium development to facilitate lung physiology at birth. In lung vasculature, Notch gene expression gradually rises from early to late lung developmental stages, suggesting that Notch pathway plays a significant role during alveolar microvasculature development (Post et al., 2000; Taichman et al., 2002; Xu et al., 2010). This suggestion is consistent with the identified role of Notch signaling in whole-body vascular development (Holderfield and Hughes, 2008; Siekmann et al., 2008). Most mutants with complete deletion of Notch ligand and such receptor genes as Notch-1, Notch-2, Dll-1, and Jag-1 die during the early embryonic developmental process; therefore, the appropriate role of the Notch gene in microvasculature development of the distal lung is still unclear. Nevertheless, some facts supporting the role of Notch signaling in peripheral lung microvasculature development arise from Foxf-1 heterozygous mutants, where Foxfi-1 haploinsufficiency mutant showed abnormal morphogenesis of lung microvasculature and lethality of neonates, owing to disruption of pulmonary expression of Notch-2 signaling and HES-1, even though disrupted Notch-2 expression and the directly affected cell type, by Foxf-1 haploinsufficiency, remains unclear (Kalinichenko et al., 2004). Notch-3 and Notch-4 null mice demonstrated almost normal lung physiology and were viable (Krebs et al., 2000; Domenga et al., 2004), whereas aberrant activation of Notch-4 in vascular endothelium exhibited pulmonary arteriovenous shunts resulting from vessel-sprouting inhibition and overgrowth of the vessel at the capillary bed interface (Miniati et al., 2010). The requirements of Notch and its transcription factors during lung development are substantially depicted in Table 3.

Pulmonary Vascular Development. The pulmonary vascular system at birth is subjected to a striking switch from a low-flow and low-pressure fetal status to a high-flow and higher-pressure postnatal status. The essential roles of Notch signaling in the vascular development have been supported by the fetal lethality of Notch signaling deficiency. For instance, either knockout of Notch-1, Dll-4, Jag-1, Notch-1 plus Notch-4, HERP-1 plus HERP-2, and presenillin-1 or continuous Notch-4 expression in mice or zebrafish led to embryonic death owing 
TABLE 3

Notch pathway gene knockout and lung phenotypes

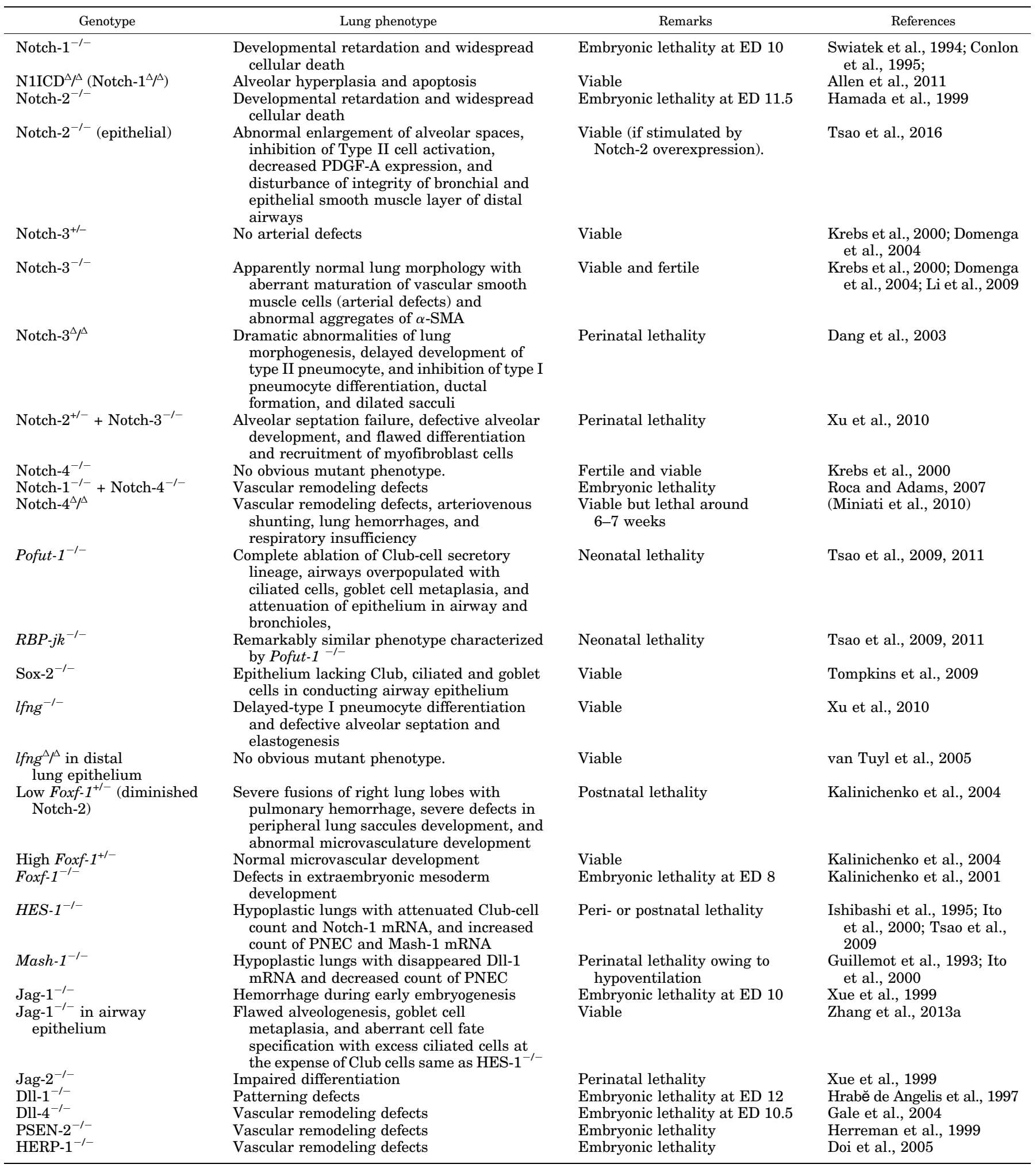

$+/-$, Deletion of single allele (heterozygous); -/-, Null allele (homozygous); $\Delta / \Delta$, overexpression of specific gene; PSEN-1, Presenilin 1.

to vascular remodeling defects (Gridley, 2007, 2010; Roca and Adams, 2007; Miniati et al., 2010), but its exact role in coordination of pulmonary vascular development remains ambiguous because of limited data.
Notch-3 receptor in embryonic pulmonary vascular smooth muscle cells is activated from an intracellular compartment (Ghosh et al., 2010). Defects in lung vascular smooth muscle have been reported in Notch-3-deficient mice, which were 
viable throughout adulthood without other apparent lung abnormalities ( $\mathrm{Li}$ et al., 2009). In this context, Ghosh and colleagues (2011) reported apparently similar morphology in Notch-3-deficient and wild-type (ED 18.5) mice at postnatal day 3. Vascular smooth muscle cells were noncohesive, dysmorphic, and vacuolated, with disordered smooth muscle $\alpha$-actin ( $\alpha$-SMA) distribution, in the Notch-3-deficient mice. They reported that Notch-3 is expressed primarily in pulmonary artery vascular smooth muscle cells-derived Jag-1, which is activated from late fetal to early postnatal life, and played a role in maintaining the morphologic characteristics and gene expression profile of the pulmonary artery after birth. Moreover, Notch-3 activation promotes proliferation of the pulmonary vascular smooth muscles cell HES-1/p27Kip1-signaling pathway (Song et al., 2015).

\section{Notch Signaling as a Potential Biomarker in Asthmatic Airway Remodeling;}

Immunologic Role of Notch Signaling in Allergic Asthmatic Airway Remodeling. Allergic asthmatic airway remodeling is characterized by infiltration of many inflammatory cells such as lymphocytes (T-lymphocytes), macrophages, neutrophils, mast cells, and eosinophils (Pascual and Peters, 2005). These inflammatory cells exhibit defensive roles in the pathogenesis of asthma. Activation of $\mathrm{CD} 4^{+} \mathrm{T}$ cells or Th-cells into Th- 1 and Th- 2 cell types, and Th-1/Th-2 imbalance (particularly an elevated level of Th-2), perform an important role in the pathogenesis of chronic asthma (Elias et al., 1999). Interleukins, such as IL-4, IL-5, IL-13 and IL-20, released as a result of Th-2 reactions, drive the asthmatic airway remodeling by interacting with airway smooth muscle cells and epithelial cells (Gong et al., 2014).

Notch/RBP-j $\kappa$ in $\mathrm{CD} 4^{+} \mathrm{T}$ cells exhibit the pivotal role in the induction of allergic asthma (KleinJan et al., 2013), because Notch is involved in the differentiation of $\mathrm{CD} 4^{+} \mathrm{T}$ cells into Th-1/Th-2 (Zhang et al., 2013b), and $\gamma$-secretase inhibitor reduced allergic asthma and goblet cell metaplasia by attenuating the Th-2 cytokine production (Kang et al., 2009). Elicitation of Th-2 cells requires GATA-3 (transcription factor) (Tanigaki et al., 2004). Notch directly governed the expression of GATA-3, and Notch and GATA-3 synergistically activated the IL-4 expression and Th-2 cell responses (Fang et al., 2007); this was further confirmed by inhibition of Notch/GATA-3 signaling pathway that resulted in the prevention of deterioration owing to allergic asthma (Chong et al., 2014). Further, intravenous immunoglobulin ameliorated allergic asthma by enhancing the Dll-4 levels, and by decreasing the GATA-3 levels and Jag-1expression, suggesting the suppression of expected Th-2 response (Kaufman et al., 2011). Moreover, in asthma models, Notch and phosphoinositide-3-kinase (PI3K) coordinately regulated the activation and differentiation of T lymphocytes via downregulation of $\mathrm{p} 27^{\mathrm{kip} 1}$ of $\mathrm{CD}^{+} \mathrm{T}$ lymphocytes and upregulation of cyclin D-1 of lymphocytes (Zhang et al., 2013b), whereas CD4 ${ }^{+} \mathrm{T}$ lymphocytes exhibited the crucial role in regulation of asthmatic airway remodeling (Foster et al., 2002). Besides $\mathrm{CD}^{+}{ }^{+} \mathrm{T}$-cell, regulatory T-cell (Treg), and Th-17 cells also exhibit a role in asthma (Shi et al., 2011). For instance, $\gamma$-secretase inhibitor $(\mathrm{L} 685,458)$ alleviated inflammation-induced allergic asthma in mice by downregulating the differentiation of Th-17 cells (Zhang et al., 2015a). In addition, in vivo study has recently shown that Notch signaling in T cells, but not Jag- 1 or Jag- 2 on dendritic cells (DCs), is important for the induction of house dust mitemediated Th-2 responses, eosinophilia, and airway hyperreactivity (Tindemans et al., 2017).

Eosinophils also exhibit the vital role in allergic asthma (Gaurav et al., 2014), and Notch regulates the differentiation and maturation of eosinophils via ERK pathway (Kang et al., 2005,2007 ), and histone deacetylation of $\mathrm{T}$ lymphocytes and $\gamma$-secretase inhibitors inhibited the eosinophilic airway inflammation (Kang et al., 2009; Zhang et al., 2015b). In granulocyte-macrophage-colony-stimulating factor-stimulated eosinophils, activation of Notch receptors and subsequent transcription of HES-1has been reported (Radke et al., 2009; Liu et al., 2015). Total ablation of eosinophil lineage in mice resulted in elevated mucus secretion and airway hyperresponsiveness similar to wild-type (acute and chronic phases), whereas eosinophil-deficient mice were considerably protected from deposition of airway smooth muscle cells and peribronchiolar collagen (Humbles et al., 2004). Various studies have demonstrated that eosinophils contribute to asthmatic airway remodeling through the secretion of cytokines (TGF- $\beta$ ) and eosinophil cationic protein, as well as through interaction with epithelial cells and mast cells (Kay et al., 2004; Venge, 2010). More detailed studies are required to evaluate the remarkable role of Notch in airway remodeling in response to allergic asthma.

Mucous/Goblet Cell Metaplasia. Mucous/goblet cell metaplasia is the hallmark of airway diseases in epithelial remodeling. Mucus, comprising Muc5AC and Muc5B, is secreted by the goblet cells and submucosal glands of the lung through epidermal growth factor receptor signaling and STAT6 activation, via IL-4, IL-5, and IL-13, during allergic disease, particularly asthma (Justice et al., 2002; Boucherat et al., 2013). The role of Notch signaling in the goblet cell metaplasia and mucus overproduction remains somewhat controversial. For instance, ablation of Notch signaling either by conditional inactivation of Pofut- 1 or by deletion of RBP-j $\kappa$ in mice resulted in striking goblet cell metaplasia and mucus metaplasia associated with significant downregulation of bHLH transcription repressor HES-5 (Tsao et al., 2009, 2011), whereas Jag-1 deletion-induced mucous metaplasia is mainly accompanied by downregulation of HES- 1 and HES- 5 (Zhang et al., 2013a). Another study has reported that Notch signaling directly downregulated the expression of Muc5AC via an HES-1-dependent mechanism (Ou-Yang et al., 2013). These findings suggest an inhibitory function of Notch in mucus overproduction and goblet cell metaplasia in asthmatics. However, in contrast, various studies have proposed that Notch signaling directly promotes the mucous metaplasia and goblet cell metaplasia (Rock et al., 2011; Danahay et al., 2015; Lafkas et al., 2015). Activation of Notch signaling in the entire lung epithelium (Guseh et al., 2009) or in airway basal cells (Rock et al., 2011) resulted in an elevated count of goblet cells and mucous cells. Most importantly, Notch ligandtreated STAT6-null cultured tracheal epithelial cells were able to cause mucous metaplasia, and unchanged expression of FOXA2 was noticed as well, demonstrating that Notch signaling acts via the STAT6-independent pathway; probably Notch and STAT6 may operate in parallel to promote goblet cell metaplasia (Guseh et al., 2009). FOXA2-independent goblet cell metaplasia was noticed in Hoxa-5 deficient mice 
accompanied by increased activity of Notch signaling, whereas $\gamma$-secretase inhibitor attenuated the goblet cell metaplasia (Boucherat et al., 2012). In addition, forced expression of the Notch-1 intracellular domain in lung epithelial cells induced both epidermal growth factor receptor (EGFR) and ERK phosphorylation with a Muc5AC expression even in the absence of epidermal growth factor. The phosphorylation of ERK induced by exogenous NICD was inhibited by a $\gamma$-secretase inhibitor (L-685,458) or introduction of small-interfering RNA directed against Notch-1 that antagonizes EGFR activity, indicating that Notch signaling induced Muc5AC expression by activating the EGFR pathway (Kang et al., 2011). Consistent with previous studies, antagonizing Notch prevented and reversed IL-13- and allergen-driven goblet cell metaplasia (Guseh et al., 2009; Kang et al., 2009; Danahay et al., 2015; Lafkas et al., 2015), as well as overturning the human airway epithelium disorder (Gomi et al., 2016), providing evidence to support the involvement of Notch signaling in goblet cell metaplasia and asthmatic airway remodeling. Taken together, controversies regarding the role of Notch in mucous/goblet cell metaplasia might might result from the disparate function of Jagged1 and Dll-4 in the pathogenesis of allergic asthma (Huang et al., 2017).

Extracellular Matrix Production and Subepithelial Fibrosis. Subepithelial fibrosis, the most distinctive pathologic characteristic of asthmatic airway remodeling (Elias et al., 1999), is characterized by unnecessary deposition of extracellular matrix (ECM). Type-I collagen, tenascin-C (TN-C), periostin, and hyaluronan are the imperative components of ECM that serve as biomarkers of asthma and scaffolds for continuing airway remodeling. Type-I collagen, heterotrimer of two $\alpha 1(\operatorname{col} 1 \alpha 1)$ and one $\alpha 2$ collagen $(\operatorname{col} 1 \alpha 2)$ subunits, becomes most abundant during subepithelial fibrosis. Recently, an in vitro study both in human (MRC-5 cells) and mice (L929 cells) lung fibroblast cell lines demonstrated that Notch signaling might regulate the expression of $\operatorname{col} 1 \alpha 1$ and $\operatorname{col} 1 \alpha 2$ via HES1-dependent mechanism (Hu et al., 2014). Subsequent in vivo study in asthmatic mouse models revealed excessive expression of type-I collagen, whereas KyoT2, a negative regulator of Notch signaling, alleviated the subepithelial fibrosis through HES-1-dependent mechanism ( $\mathrm{Hu}$ et al., 2015).

TN-C is involved in the pathogenesis of bronchial asthma (Rogers et al., 2012), whereas its deficiency attenuates the allergen-induced bronchial asthma (Nakahara et al., 2006). Notch signaling regulates the endogenous TN-C expression via RBP-j $\kappa$-induced target gene (Sivasankaran et al., 2009). Recently, Sarkar and colleagues (2017) have shown that integrin $\alpha 2 \beta 1$ might be a direct link between TN-C and Notch signaling. It will be important to study the involvement of TN-C regulation in Notch-deficient asthmatic mice to clarify the relationship between $\mathrm{TN}-\mathrm{C} / \mathrm{Notch}$ and asthmatic airway remodeling.

Hyaluronan, a polysaccharide of ECM, is found within the peribronchial and perialveolar spaces of the healthy lung. During inflammation, smaller fragments of hyaluronan that are proinflammatory in nature are produced; they affect other ECM components, including collagen I and II, and are potentially associated with airway remodeling, hyperresponsiveness, and clinical symptoms (Garantziotis et al., 2016). Hyaluronan regulates the expression of Notch genes because expression of Notch-1 mRNA decreases whereas
Notch-3 mRNA increases significantly compared with controls when normal human epidermal keratinocytes were incubated in dishes coated with sulfated hyaluronan (Nagira et al., 2007). Periostin is a multifunctional protein that is upregulated in response to IL-4 and IL-13 in airway epithelial cells and lung fibroblasts of asthmatics. Periostin is involved in many aspects of asthma, such as eosinophil recruitment, airway remodeling, development of a Th2 phenotype, and increased expression of inflammatory mediators ( $\mathrm{Li}$ et al., 2015). Interestingly, Notch-1 is downregulated in periostindeficient mice, suggesting that periostin could directly interact with Notch-1 precursor to stabilize the Notch-1 expression and subsequent signaling. Moreover, periostin directly interacts with type-I collagen (Norris et al., 2007), fibronectin, and TN-C (Kii et al., 2010). Through these interactions, periostin seems to induce airway remodeling via modulation of ECM production. To date, limited data are available to support the participation of Notch in EMC, its components and production, and airway epithelium and/or subepithelial fibrosis in asthmatics. Hence, more profound studies are needed.

Myofibroblast Differentiation. All Notch receptors, except Notch-4, are accomplished with the regulation of myofibroblast differentiation. Notch-1/CSL activation induced the differentiation of myofibroblast through direct regulation of $\alpha$-SMA (Noseda et al., 2006), and $\alpha$-SMA is normally used as a molecular marker for myofibroblasts. Knockout mice study has demonstrated that Notch-1 exhibited a distinct role in stimulating the $\alpha$-SMA gene expression (Liu et al., 2009), whereas Notch- 2 inhibited the TGF- $\beta$-induced collagen-I and $\alpha$-SMA gene expression via downregulation of the Notch-3 in myoblasts (Ono et al., 2007). However, in 10T1/2 fibroblasts, overexpression of activated Notch-3 blocked the TGF- $\beta 1$ dependent smooth muscle-specific genes, such as $\alpha$-SMA, by inhibiting the activation of Smad-3 and p38 mitogen-activated protein kinase (Kennard et al., 2008), whereas TGF- $\beta 1$ decreased the Notch-3 expression but unexpectedly HES-1was up-regulated. It has also been suggested that fibroblast proliferation is inhibited by Notch-1 and is mediated through Wnt-1-independent but Wnt-11-dependent Wnt-1-inducible signaling pathway protein 1 expression (Liu et al., 2012). In contrast, Notch-1 actively induced the differentiation of myofibroblast of alveolar epithelial cells through a TGF- $\beta-$ Smad-3 pathway that activates $\alpha$-SMA gene transcription in a TGF- $\beta$ control element-dependent manner and SRF-binding site [CC(A/T)6GG, also termed as CArG box]-dependent or CArG-dependent manner (Aoyagi-Ikeda et al., 2011). Interestingly, physiologic differentiation of myofibroblasts during lung alveogenesis required the involvement of $l$ fng-mediated Notch signaling (Xu et al., 2010). Notch in alveolar type 2 cells induced PDGF-A expression to expand the cell population of myofibroblasts (Tsao et al., 2016). Hence, the consequences of Notch signaling in fibrosis (Kavian et al., 2012) might be the result of activation of myofibroblast differentiation via endothelial-mesenchymal transition and epithelialmesenchymal transition.

Epithelial-Mesenchymal Transition. Dysregulation of epithelial barrier function is a pathologic hallmark of asthmatic airway remodeling that leads to transdifferentiation of epithelial cells to attain mesenchymal characteristics, such as the production of extracellular matrix, $\alpha$-SMA, and vimentin, and enhanced motility, in a process known as epithelial-mesenchymal 
transition (EMT). Transcription factors including Snail-1, Slug (Snail-2), Twist-1/2, and zinc finger E-box-binding homeobox-1/2 (ZEB-1/2) serve as phenotypic markers of EMT. Slug, Snail, SIP1/ZEB, Twist, and E-47 negatively control E-cadherin expression. Notch crosstalks with numerous transcription and growth factors related to EMT, such as Snail, Slug, PDGF, fibroblast growth factor (FGF), and TGF- $\beta$ (Gonzalez and Medici, 2014). Notch upregulated the Snail and Slug that subsequently led to transcriptional repressors of CDH1(E-cadherin gene), alleviation of the cell-cell junction, and destabilization of epithelial structure (primary step in EMT) (Leong et al., 2007). Notch-1 knockdown in intestinal epithelial cells contributed to decreased barrier function, a decline in the expression of intercellular tight junction protein Claudin-5, and increased intercellular permeability (Mathern et al., 2014). Overexpression of Notch alone upregulated Snail expression and downregulated E-cadherin, whereas inactivation of Notch decreased the Snail expression and attenuated the downregulation of E-cadherin expression, suggesting the participation of Notch signaling in EMT induction via Snail (Xie et al., 2012). Notch signaling-induced EMT could trigger the upregulation of mesenchymal markers (Snail, Slug) and downregulation of epithelial markers (E-cadherin) in the cardiac valve and cushion formation, human kidney epithelial cells, and non-small cell lung cancer cell lines. Importantly, Loffredo et al. (2017) recently identified Notch-2, among other recognized genes, as a novel marker central to dysregulation of epithelial-mesenchymal signaling in asthmatics and suggested that the EMT process, concerned with asthma pathogenesis, is a manifestation of an underlying profound and persistent suppression of epithelial differentiation, because significant suppression of epithelial differentiation was demonstrated in the scarcity of Notch signaling. Moreover, inactivation of Notch signaling by a $\gamma$-secretase inhibitor could reverse the EMT process, highlighting the direct involvement of Notch signaling in EMT induction, making Notch signaling attractive targets for new therapeutics.

Of note, EMT in non-small cell lung cancer is mediated by TGF- $\beta$, which promotes the interface of SMAD to the promoters of Snail. Crosstalk between Notch and TGF- $\beta$ is imperative for induction of EMT, because Notch signaling is required to maintain $\mathrm{TGF} \beta$-induced expression of $\mathrm{HEY}-1$, and pharmacological inactivation of Notch and/or knockdown of HEY-1 or jag-1 could inhibit the TGF- $\beta$-induced EMT, demonstrating the key role of Notch signaling in TGF- $\beta$-induced EMT (Zavadil et al., 2004). Similarly, in alveolar epithelial cells, Notch- 1 activated the $\alpha$-SMA gene in a TGF- $\beta$ control element-dependent manner and a CArG-dependent manner through TGF- $\beta$-Smad-3 pathway (Aoyagi-Ikeda et al., 2011). Meanwhile, pharmacological inhibition of Notch signaling could notably inhibit the TGF- $\beta$-induced expression of $\alpha$-SMA, signifying Notch-induced EMT via TGF- $\beta$-Smad-3 pathway (Matsuno et al., 2012). Nevertheless, Notch prevented TGF- $\beta$-mediated EMT in cultured cells through Smad7 induction (Tsai et al., 2014). Collectively, these studies indicate that the crosstalk between Notch signals and TGF- $\beta$ play an insightful role in EMT, and more detailed studies are needed to evaluate the role of Notch signaling in EMT-induced asthmatic airway remodeling.

Pulmonary Vascular Remodeling. Pulmonary vascular remodeling, including increased subepithelial vascularity and microvascular leakage, is significantly increased in asthmatics with the severity of asthma (Shifren et al., 2012). Multiple factors are involved, including inflammatory mediators (pro-inflammatory mediators such as IL-6 and -8, TNF- $\alpha$, TGF- $\beta$ ), extracellular matrix proteins, bioactive extracellular matrix fragments (matrikines), growth factors (FGF family, PDGF, TGF- $\beta$, TNF- $\alpha$, and IL-1family), and proteases (matrix matlloproteinases and ADAMs) (Harkness et al., 2015). The enhanced vasculogenic effect in pulmonary tissue is determined by the Th-1- and Th-2-dependent selection predisposition in T-cells, which act as chemotactic substances for endothelial precursor cells, such as VEGF-A, to induce Th-2type inflammatory responses that are proinflammatory and lead to the angiogenic switch.

Notch-3/Jagged controls the differentiation and expansion of Treg (Anastasi et al., 2003), and Treg exhibits the angioregulatory response (Asosingh et al., 2007). So, Notch signaling demonstrates a crucial role in angiogenesis and vasculogenesis (Iso et al., 2003). Activation of Notch-HES-1 axis via TGF- $\beta$ exhibited Treg-mediated immunosuppression (Ostroukhova et al., 2006). Injection of sensitized Treg cells in a chronic mouse asthma model alleviated the airway remodeling by reducing the pulmonary vasculature via induction of apoptosis through a Dll-4/Notch signaling pathway (Huang et al., 2009). Dll-4 and Jag-1 surprisingly demonstrated the different responses in asthma models (Huang et al., 2017). Dll-4 alleviated the airway hyper-responsiveness by suppressing neovasculature airway remodeling via Treg (Huang et al., 2009), and Jag-1 initiated allergic asthma by stimulating the Th-2 differentiation and IL-4 production, leading to airway inflammation, airway hyperresponsiveness, and asthmatic airway remodeling (Okamoto et al., 2009).

As discussed, Notch signaling is imperative for regulation of proximodistal cell fates, pseudostratified epithelium differentiation, pulmonary neuroendocrine cell differentiation, pulmonary goblet cell fate, and alveolar and pulmonary vasculature development. Deletion and/or deterioration of Notch signaling during early lung development leads to abnormal enlargement of alveolar spaces, disturbance of the integrity of bronchial and epithelial smooth muscle layers (Tsao et al., 2016), widespread cellular death (Swiatek et al., 1994; Hamada et al., 1999), aberrant maturation of vascular smooth muscular cells (Krebs et al., 2000), vascular remodeling defects (Gale et al., 2004; Roca and Adams, 2007), hypoplastic lungs with attenuated Club cells count (Tsao et al., 2009; Morimoto et al., 2010), and goblet cell metaplasia (Tsao et al., 2011; Danahay et al., 2015; Lafkas et al., 2015). These pathologic changes elaborate the underlying causes for abnormal lung functioning. Moreover, Notch genes participating in fetal lung development may clarify the molecular processes involved in lung function impairment, but clinical data to support the role of Notch signaling in linking lung development and asthmatic airway remodeling is yet missing. However, murine model studies suggest that abnormal in utero expression of Notch genes, concerned with healthy lung development, can result in impaired lung physiology after birth. Review of all data suggests that Notch signaling exhibits a distinct but mysterious role in linking lung development and asthmatic airway remodeling, therefore detailed experimental and genetic studies are needed to investigate the underlying philosophy. 


\section{Notch Signaling as a Potential Therapeutic Target}

As Notch signaling exhibits a potential role in the regulation of asthmatic airway remodeling, direct or indirect targeting of Notch pathways at signal sending-signal receiving sites, intracellular signaling levels, transcriptional/ post-transcriptional levels, specific cofactor action sites, and crosstalk with other pathways would facilitate development of new effective therapeutic approaches to control/reverse asthmatic airway remodeling (Fig. 3).

Targeting Notch Signaling via $\gamma$-Secretase Inhibitors. $\gamma$-Secretase inhibitors, which are nonspecific Notch pathway inhibitors, inhibit the S3 cleavage that subsequently inhibits the production of NICD from membrane-tethered Notch receptors and transcription of target genes. $\gamma$-Secretase inhibitors are divided into three main classes: peptide isosteres, azepines, and sulfonamides. L685458, MW167 (gamma-secretase inhibitor II), and DAPT (also known as GSI-IX and Compound 3) are reversible peptide-based $\gamma$-secretase inhibitors. From DAPT, LY-411575 (compound 5; 100-fold stronger than DAPT), LY-450139 (compound 6) and RO-4929097 (Roche, Nutley, NJ) have been developed that are even more effective. DBZ (dibenzazepine or YO-01027) and JLK6 are irreversible azepine-based $\gamma$-secretase inhibitors. MK-0752 and compound 18 are sulfonamide-based $\gamma$-secretase inhibitors. Various clinical trials are ongoing to explore how and whether targeting Notch signaling via $\gamma$-secretase inhibitors can alleviate different ailments, particularly in oncology, and in the case of asthmatic airway remodeling, few approaches have been performed via antagonizing $\gamma$-secretase.

In an asthma model, L685458 alleviated allergic asthma phenotypes via downregulation of Th-2 cytokine production (Kang et al., 2009) and antagonized the differentiation of Th-17 cells (Zhang et al., 2015a). L685458 vitiated the airway goblet cell metaplasia in a Hoxa-5 mutant mouse model
(Boucherat et al., 2012). In asthma models, MW167 attenuated the Th- 2 polarization, airway inflammation, and the levels of IL-4 and IL-5 in BALF and serum compared with PBS-treated (Zhou et al., 2015). Furthermore, DAPT reversed the pathologic remodeling of airway epithelium (Gomi et al., 2015) and attenuated the accumulation of eosinophils in allergic airways (Liu et al., 2015). In human airway epithelial cells, DBZ attenuated the IL-13-induced airway mucous metaplasia either independently of STAT-6 or downstream of the STAT-6 pathway (Guseh et al., 2009). Treating $\mathrm{CD}^{+}{ }^{+} \mathrm{T}$ cells with DBZ resulted in inhibition of Th-2 differentiation, IL-4 production, airway hyper-responsiveness, and eosinophilic airway inflammation (Okamoto et al., 2009). Importantly, like other key growth factors and signaling pathways, appropriate Notch level is needed for normal airway development and homeostasis. Nonspecific inhibition of Notch pathway via $\gamma$-secretase inhibitors may cause many unpredictable negative effects. Therefore, more specific $\gamma$-secretase inhibitors for a bench-to-bedside therapeutic application need to be developed.

Targeting Notch Signaling Other than $\gamma$-Secretase Inhibitors. Fringe (fucose- $\beta 1, \quad 3-N$-acetyl glucosaminyl transferases) regulates Notch signaling via ligand-receptor binding, and Notch signaling regulates the development and differentiation of T-helper cells. An OVA-sensitized asthmatic rat model has shown significantly low expression of both manic fringe ( $m f n g$ ) and lunatic fringe (lfng) compared with radical fringe ( $r f n g$ ) (Gu et al., 2012). Overexpression of $l f n g$ in $\mathrm{CD}^{+}{ }^{+} \mathrm{T}$ cells in asthmatic rats, using lfng plasmid, inhibited the Th-2 cytokine production in a Notch-dependent manner (Gu et al., 2012), suggesting that overexpression of lfng may be helpful in treating Th-2 cytokine-associated asthma. In contrast, an increased expression of lfing has been reported in respiratory syncytial virus (RSV)-induced asthma models. Accordingly, STAT-5-dependent lfng expression in Th-2 development augmented the Dll4-Notch-mediated IL-4 release

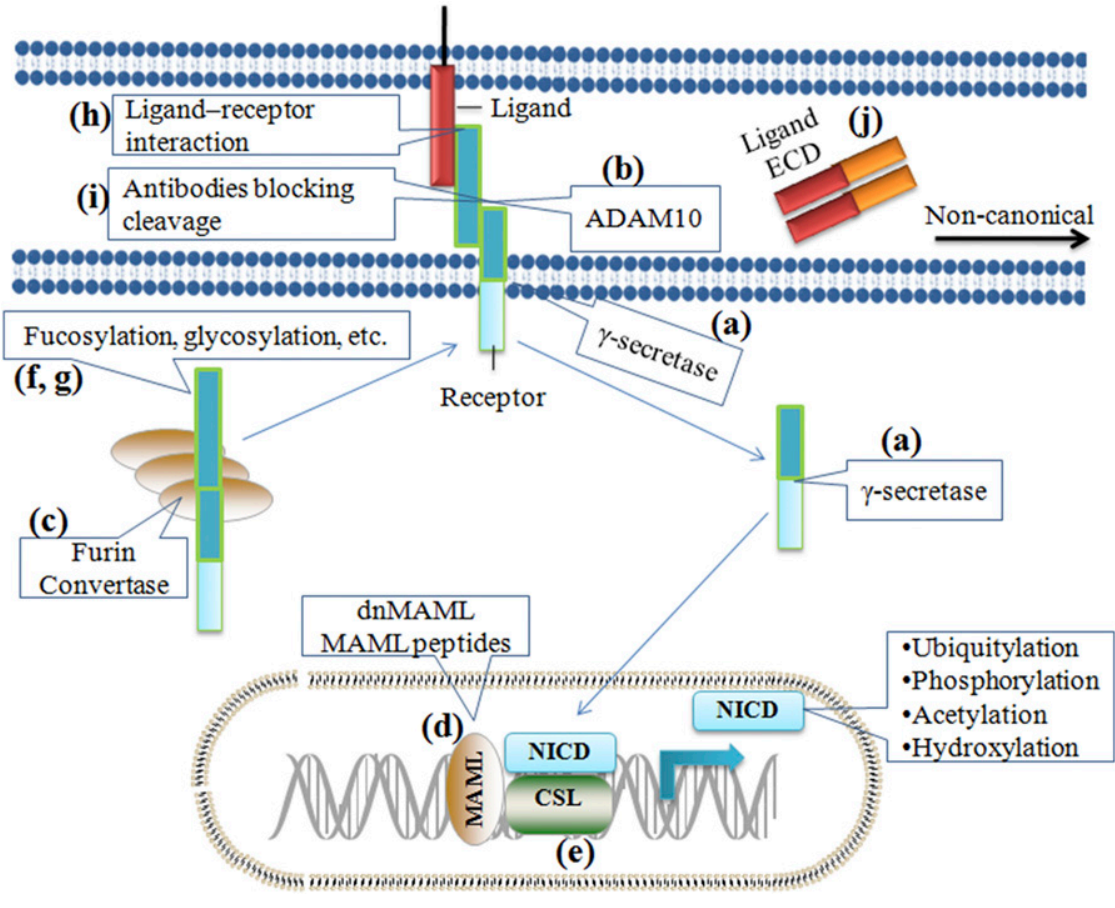

Fig. 3. Therapeutically effective components of Notch pathway to treat asthmatic airway remodeling. There are several therapeutically effective nodes in the Notch signaling pathway, some are putative targets for new drug intervention. Cleavage by $\gamma$-secretase (a), ADAM secretase (b), and furin (c) can be targeted pharmacologically and are under preclinical studies to treat asthmatic airway remodeling. Interfering with the interaction between NICD and MAML (d) or CSL (or RBP-jк) (e) nullify Notch signaling. Interfering with fucosylation, glycosylation (f), or other EGF-specific modifications (g) by inhibiting fringe activity may modulate specific Notch pathways. Similarly, Notch antibodies targeting Notch ligands (h) or receptors (i) would exclusively target individual receptor pathways. Finally, Notch ligand fusion peptides (j) can be used as an effective target. dnMAML, dominant-negative MAML. 
during RSV-induced allergic asthma, whereas genetic deletion of lfng inhibited the Dll4-mediated Notch activation, Th- 2 cytokine production, and IL-4 release (Mukherjee et al., 2014). These studies suggest that fringe could be a new curative approach for the impediment of allergic asthma and airway remodeling, so it cannot be discounted. Therefore, more studies are needed to elucidate the exact role of fringe in the pathogenesis of asthma and to explore whether interference with fringe is a feasible treatment.

Dll-4 expressed on dendritic cells influence the differentiation of T-helper cells toward Th-1 and Th-2 or Treg (Amsen et al., 2009). Dll-4 neutralization exacerbated the IL-5 and IL-13 production, Th-2 cytokine production, and airway hyper-responsiveness during RSV infection (Schaller et al., 2007; Jang et al., 2010; Ting et al., 2017), whereas Dll-4 activation during differentiation sustained Treg cell phenotype and function to control RSV infection (Ting et al., 2017). Moreover, intravenous administration of OVA-pulsed plus Dll4-pretreated DCs in Th-2-dominant asthmatic murine models notably increased the production of IL-10, reduced the production of proinflammatory cytokines, decreased the severity of airway hyper-responsiveness, and alleviated the expression levels of OVA-specific IgE, indicating that Dll-4 altered the DC activation (Huang et al., 2013). In contrast, in vivo neutralization of Dll-4 remarkably decreased the Th- 2 cytokines production, mucus production, and airway hyperreactivity, whereas Dll4-mediated Notch activation during viral exacerbation further augmented the lfng-dependent Th-2 cell activation (Mukherjee et al., 2014). It would be reasonable to hypothesize that allergen-induced Th-2 inflammatory surroundings are used by virus to further intensify the allergic circumstance most probably owing to RSV-induced pro-Th-2 factors (IL-25) (Kaiko et al., 2010) and thymus and activation-regulated chemokine (Monick et al., 2007) that ultimately amplify the development and recruitment of Dll4mediated Th-2 cytokine in the lung. Hence, these observations suggest that Dll-4 could be an effective therapeutic target for modulating airway hyper-responsiveness and chronic asthma, but it is difficult to justify the exact role of Dll-4-mediated Notch signaling because of either the complexity of Notch receptor-ligand interactions or participation of noncanonical Notch pathways. Nonetheless, continuous attention is required to explore the exact role of Dll4-mediated Notch signaling to treat asthmatic airway remodeling.

Natural regulatory T cells (nTreg; $\mathrm{CD}^{+}{ }^{+} \mathrm{CD} 25^{+}$) or induced regulatory $\mathrm{T}$ cells (iTreg) can effectively attenuate the features of allergic airway inflammation and inhibit the development of airway remodeling (Kearley et al., 2008; Lan et al., 2012), and Notch/Jagged controls the differentiation and expansion of Treg cells (Hoyne et al., 2000); in particular, constitutive Notch-3 activation enhanced the Treg cell generation (Anastasi et al., 2003). Adoptive transfer of iTreg (Xu et al., 2012) and Dll4expressing Treg (Huang et al., 2009) to an OVA-sensitized chronic asthma mouse model effectively alleviated the airway remodeling. Moreover, administration of Dll4-expressing antigen-presenting cells in OVA-induced murine asthma model ameliorated allergic asthma via induction of Treg-mediated regulatory pathway, whereas blockage of Dll-4 impaired the Treg differentiation, and resulted in exaggerated asthma phenotypes (Huang et al., 2017). Hence, Treg needs to be further investigated in established airway remodeling to determine the importance of this therapeutic approach.
The pseudostratified airway epithelium is layered by the balanced proportion of secretory and ciliated cells, accompanied by undifferentiated basal cells, which differentiate to basal stem cells (goblet cell hyperplasia) during asthma. An adult trachea study has shown that persistent activation of Notch impeded ciliogenesis and endorsed the luminal differentiation of the basal cell into secretory cells (Rock et al., 2011). Consistent with this, STAT-3 activated by IL-6 produced in response to injury, promoted multiciliogenesis and regeneration of airway multiciliated cells from basal cells through upregulation of ciliogenesis genes, such as Foxj1 and Mcidas, and through downregulation of Notch-1(Tadokoro et al., 2014). Interestingly, signaling pathway between Toll-like receptor 4 and Notch-1 might coordinate with STAT-3, because expression levels of Toll-like receptor 4 and Notch-1, and phosphorylation of STAT-3 in asthma models was increased but decreased after Cornuside, a natural secoiridoid glucoside, treatment (Zheng, 2016). Hence, modulation of ciliogenesis by IL-6/STAT-3, via direct regulation of Notch-1, might prove helpful to prevent/treat the asthmatic airway remolding.

$\mathrm{RBP}-\mathrm{j} \kappa$ along another transcriptional complex (NICD-CBF-1/ RBP-j $\kappa-M A M L)$ induces the transcription of target genes, whereas targeting/inactivation of RBP-j $\kappa$ inhibits the RBP-j $\kappa$ mediated transcription and Notch pathway. KyoT2, the negative regulator of Notch pathway, inhibits RBP-j $\kappa$-mediated transcriptional activation (Collins et al., 2014). Hu et al. (2015) showed that KyoT2 downregulated asthmatic airway remodeling by alleviating the subepithelial fibrosis and airway hyper-responsiveness through the HES1-dependent mechanism as well as improved lung function, suggesting that targeting/inactivation of RBP-j $\kappa$ might act as a potential clinical treatment strategy for asthmatic airway remodeling in future.

The epigenetic study revealed that asthma is linked with epigenetic changes in the Notch-l promoters, such as abnormal histone acetylation and methylation (Cui et al., 2013). Cui and colleagues investigated the histone modification of asthmatic lung $\mathrm{CD}^{+} \mathrm{T}$ cells and revealed that histone acetylation and trimethylation levels of Notch-l gene promoter P300 and pCAF activities were remarkably elevated compared with control. Although histone acetyltransferase activity, expression levels of Notch-1 and HES-I, and asthmatic parameters such as IL-4, IL-5, and IL-13 were significantly decreased after the intervention of asthmatic lung $\mathrm{CD}^{+}{ }^{+} \mathrm{T}$ cells with garcinol, a potent natural inhibitor of histone acetyltransferases, p300, and pCAF (Cui et al., 2013), suggesting that targeting histone acetylation might be a new therapeutic strategy for the appropriate regulation of the Notch signaling pathway and for the treatment of asthmatic airway remodeling.

In summary, our ever-increasing understanding of the Notch signaling pathway offers great hope that specific targeting of Notch signaling may represent a promising alternative complementary therapeutic strategy for treatment of asthmatic airway remodeling in future.

\section{Side Effects Associated with Notch Pathway Inhibition}

Although preclinical studies, on Alzheimer's disease but not on asthmatic airway remodeling, have shown that long-term interference in Notch signaling by $\gamma$-secretase inhibitors led to severe gastrointestinal toxicity, such as vomiting, nausea, 
diarrhea, decreased appetite, and inflammation owing to full inhibition of Notch pathway (Hsu et al., 2013). Importantly, Notch drives gastrointestinal precursor cells toward an epithelial fate and away from a secretory cell fate, whereas Notch inhibition results in an imbalance of this process and leads to secretory goblet cell hyperplasia (van Es et al., 2005). Additionally, inhibition of the Notch pathway leads to skin cancer (Demehri et al., 2009) and disruption of the immune system (Wong et al., 2004). Consequently, a dose-dependent effect of LY-411575 ( $\gamma$-secretase inhibitor) on the intestine, spleen, and thymus of mice has been reported (Wong et al., 2004), because LY-411575 at high- and low-dose concentrations attenuated and enhanced the $\beta$-amyloid, respectively, by modulating $\gamma$-secretase complex at different binding sites. These toxicities might be challenging for any Notch inhibitor. Therefore, some $\gamma$-secretase modulators sparing the Notch cleavage have been developed (Chávez-Gutiérrez et al., 2012). Further, NSAIDs as therapeutic agents for reducing inflammation by targeting $\gamma$-secretase are under study (Saura, 2010). To minimize these side effects, two possible strategies have been proposed: the coadministration of $\gamma$-secretase inhibitors with glucocorticoids such as dexamethasone (Real et al., 2009) and recurrent dosing plans of $\gamma$-secretase inhibitors (Purow, 2012). Both strategies have been shown to spare the gut of toxicity for the most part but maintain the desired effect.

\section{Concluding Remarks}

Although major research has been conducted to understand the role of Notch signaling in malignancies and fibroproliferative disorders, clinical data to support the role of Notch signaling in asthmatic subjects are still lacking. Evidence obtained from animal models support the crucial role of Notch signaling in embryonic lung development, initiation and progression of asthmatic airway remodeling, and linking impaired fetal lung development either with asthmatic airway remodeling directly or through other pathways. Moreover, currently identified Notch targets can be counted on a few fingers, but even in those cases, we have little knowledge. $\gamma$-secretase inhibitors and other described approaches might be effective to overcome both aberrant expression and overproduction of Notch signaling, but they are associated with unwanted effects owing to the pleiotropic nature of Notch signaling; therefore, further detailed genome-wide association studies are needed to develop more specific $\gamma$-secretase inhibitors and modulators that could easily differentiate between wellness and illness. In this regard, a better understanding of the communications of canonical and noncanonical Notch signaling, consideration of how and why different target genes are activated according to cell type and time, exploration of Notch signaling crosstalk with other pathways, and apposite targeting of Notch signaling will open a new therapeutic era. In particular, future studies aimed at delineating the precise cellular and molecular mechanisms underpinning Notch-mediated asthmatic airway remodeling suppression will be important for developing potential therapeutic strategies.

\section{Acknowledgments}

The authors gratefully acknowledge Higher Education Commission (HEC), Pakistan (Ref: OS-II/Batch-6(China)/PM/2015).

\section{Authorship Contributions}

Wrote or contributed to the writing of the manuscript: Hussain, $\mathrm{Xu}$, Ximei Wu, Ahmad, Lu, Xiling Wu, Yang, Tang.

\section{References}

Acar M, Jafar-Nejad H, Takeuchi H, Rajan A, Ibrani D, Rana NA, Pan H, Haltiwanger RS, and Bellen HJ (2008) Rumi is a CAP10 domain glycosyltransferase that modifies Notch and is required for Notch signaling. Cell 132:247-258.

Allen TD, Rodriguez EM, Jones KD, and Bishop JM (2011) Activated Notch1 induces lung adenomas in mice and cooperates with Myc in the generation of lung adenocarcinoma. Cancer Res 71:6010-6018.

Amsen D, Antov A, and Flavell RA (2009) The different faces of Notch in T-helper-cell differentiation. Nat Rev Immunol 9:116-124.

Anastasi E, Campese AF, Bellavia D, Bulotta A, Balestri A, Pascucci M, Checquolo S, Gradini R, Lendahl U, Frati L, et al. (2003) Expression of activated Notch3 in transgenic mice enhances generation of $\mathrm{T}$ regulatory cells and protects against experimental autoimmune diabetes. J Immunol 171:4504-4511.

Andersen P, Uosaki H, Shenje LT, and Kwon C (2012) Non-canonical Notch signaling: emerging role and mechanism. Trends Cell Biol 22:257-265.

Aoyagi-Ikeda K, Maeno T, Matsui H, Ueno M, Hara K, Aoki Y, Aoki F, Shimizu T, Doi H, Kawai-Kowase K, et al. (2011) Notch induces myofibroblast differentiation of alveolar epithelial cells via transforming growth factor- $\beta$-Smad3 pathway. Am J Respir Cell Mol Biol 45:136-144.

Asosingh K, Swaidani S, Aronica M, and Erzurum SC (2007) Th1- and Th2 dependent endothelial progenitor cell recruitment and angiogenic switch in asthma. J Immunol 178:6482-6494.

Beckers J, Clark A, Wünsch K, Hrabé De Angelis M, and Gossler A (1999) Expression of the mouse Delta1 gene during organogenesis and fetal development. Mech Dev 84:165-168.

Bigas A, Guiu J, and Gama-Norton L (2013) Notch and Wnt signaling in the emergence of hematopoietic stem cells. Blood Cells Mol Dis 51:264-270.

Borges M, Linnoila RI, van de Velde HJ, Chen H, Nelkin BD, Mabry M, Baylin SB, and Ball DW (1997) An achaete-scute homologue essential for neuroendocrine differentiation in the lung. Nature 386:852-855

Boucherat O, Boczkowski J, Jeannotte L, and Delacourt C (2013) Cellular and molecular mechanisms of goblet cell metaplasia in the respiratory airways. Exp Lung Res 39:207-216.

Boucherat O, Chakir J, and Jeannotte L (2012) The loss of Hoxa5 function promotes Notch-dependent goblet cell metaplasia in lung airways. Biol Open 1:677-691.

Bray SJ (2006) Notch signalling: a simple pathway becomes complex. Nat Rev Mol Cell Biol 7:678-689.

Brückner K, Perez L, Clausen H, and Cohen S (2000) Glycosyltransferase activity of Fringe modulates Notch-Delta interactions. Nature 406:411-415.

Chapman G, Liu L, Sahlgren C, Dahlqvist C, and Lendahl U (2006) High levels of Notch signaling down-regulate Numb and Numblike. J Cell Biol 175:535-540.

Chávez-Gutiérrez L, Bammens L, Benilova I, Vandersteen A, Benurwar M, Borgers M, Lismont S, Zhou L, Van Cleynenbreugel S, Esselmann H, et al. (2012) The mechanism of $\gamma$-Secretase dysfunction in familial Alzheimer disease. EMBO J 31: 2261-2274.

Chen H, Thiagalingam A, Chopra H, Borges MW, Feder JN, Nelkin BD, Baylin SB, and Ball DW (1997) Conservation of the Drosophila lateral inhibition pathway in human lung cancer: a hairy-related protein (HES-1) directly represses achaetescute homolog-1 expression. Proc Natl Acad Sci USA 94:5355-5360.

Chen JD and Evans RM (1995) A transcriptional co-repressor that interacts with nuclear hormone receptors. Nature 377:454-457.

Chen S, Lee BH, and Bae Y (2014) Notch signaling in skeletal stem cells. Calcif Tissue Int 94:68-77.

Chong L, Zhang W, Nie Y, Yu G, Liu L, Lin L, Wen S, Zhu L, and Li C (2014) Protective effect of curcumin on acute airway inflammation of allergic asthma in mice through Notch1-GATA3 signaling pathway. Inflammation 37:1476-1485.

Collins KJ, Yuan Z, and Kovall RA (2014) Structure and function of the CSL-KyoT2 corepressor complex: a negative regulator of Notch signaling. Structure 22:70-81.

Conlon RA, Reaume AG, and Rossant J (1995) Notch1 is required for the coordinate segmentation of somites. Development 121:1533-1545.

Cordle J, Redfieldz C, Stacey M, van der Merwe PA, Willis AC, Champion BR, Hambleton S, and Handford PA (2008) Localization of the delta-like-1-binding site in human Notch-1 and its modulation by calcium affinity. $J$ Biol Chem 283 : 11785-11793.

Cui ZL, Gu W, Ding T, Peng XH, Chen X, Luan CY, Han RC, Xu WG, and Guo XJ (2013) Histone modifications of Notch1 promoter affect lung CD4 $4^{+} \mathrm{T}$ cell differentiation in asthmatic rats. Int $J$ Immunopathol Pharmacol 26:371-381.

Danahay H, Pessotti AD, Coote J, Montgomery BE, Xia D, Wilson A, Yang H, Wang $\mathrm{Z}$, Bevan L, Thomas C, et al. (2015) Notch2 is required for inflammatory cytokinedriven goblet cell metaplasia in the lung. Cell Reports 10:239-252.

Dang TP, Eichenberger S, Gonzalez A, Olson S, and Carbone DP (2003) Constitutive activation of Notch3 inhibits terminal epithelial differentiation in lungs of transgenic mice. Oncogene 22:1988-1997.

de la Pompa JL (2009) Notch signaling in cardiac development and disease. Pediatr Cardiol 30:643-650.

Demehri S, Turkoz A, and Kopan R (2009) Epidermal Notch1 loss promotes skin tumorigenesis by impacting the stromal microenvironment. Cancer Cell 16:55-66. Doi H, Iso T, Yamazaki M, Akiyama H, Kanai H, Sato H, Kawai-Kowase K, Tanaka T, Maeno T, Okamoto E, et al. (2005) HERP1 inhibits myocardin-induced vascular smooth muscle cell differentiation by interfering with SRF binding to CArG box. Arterioscler Thromb Vasc Biol 25:2328-2334.

Domenga V, Fardoux P, Lacombe P, Monet M, Maciazek J, Krebs LT, Klonjkowski B, Berrou E, Mericskay M, Li Z, et al. (2004) Notch3 is required for arterial identity and maturation of vascular smooth muscle cells. Genes Dev 18:2730-2735. 
D'Souza B, Miyamoto A, and Weinmaster G (2008) The many facets of Notch ligands. Oncogene 27:5148-5167.

Elias JA, Zhu Z, Chupp G, and Homer RJ (1999) Airway remodeling in asthma $J$ Clin Invest 104:1001-1006.

Engelhardt JF, Schlossberg H, Yankaskas JR, and Dudus L (1995) Progenitor cells of the adult human airway involved in submucosal gland development. Development 121:2031-2046.

Fang TC, Yashiro-Ohtani Y, Del Bianco C, Knoblock DM, Blacklow SC, and Pear WS (2007) Notch directly regulates Gata3 expression during T helper 2 cell differentiation. Immunity 27:100-110.

Fehrenbach H, Wagner C, and Wegmann M (2017) Airway remodeling in asthma: what really matters. Cell Tissue Res 367:551-569.

Foster PS, Yang M, Herbert C, and Kumar RK (2002) CD4(+) T-lymphocytes regulate airway remodeling and hyper-reactivity in a mouse model of chronic asthma Lab Invest 82:455-462.

Fryer CJ, Lamar E, Turbachova I, Kintner C, and Jones KA (2002) Mastermind mediates chromatin-specific transcription and turnover of the Notch enhancer complex. Genes Dev 16:1397-1411.

Fryer CJ, White JB, and Jones KA (2004) Mastermind recruits CycC:CDK8 to phosphorylate the Notch ICD and coordinate activation with turnover. Mol Cell 16: 509-520.

Gale NW, Dominguez MG, Noguera I, Pan L, Hughes V, Valenzuela DM, Murphy AJ, Adams NC, Lin HC, Holash J, et al. (2004) Haploinsufficiency of delta-like 4 ligand results in embryonic lethality due to major defects in arterial and vascular development. Proc Natl Acad Sci USA 101:15949-15954.

Garantziotis S, Brezina M, Castelnuovo P, and Drago L (2016) The role of hyaluronan in the pathobiology and treatment of respiratory disease. Am J Physiol Lung Cell Mol Physiol 310:L785-L795.

Gaurav R, Bewtra AK, and Agrawal DK (2014) Novel CLC3 transcript variants in blood eosinophils and increased CLC3 expression in nasal lavage and blood eosinophils of asthmatics. Immun Inflamm Dis 2:205-213.

Ghosh S, Paez-Cortez JR, Boppidi K, Vasconcelos M, Roy M, Cardoso W, Ai X, and Fine A (2011) Activation dynamics and signaling properties of Notch3 receptor in the developing pulmonary artery. $J$ Biol Chem 286:22678-22687.

Ghosh S, Vasconcelos M, Roy M, Ai X, Cardoso W, Fine A, and Paez-Cortez J(2010 Notch 3 receptor is localized and activated from an intracellular compartment in embryonic lung vascular smooth muscle cells. Am J Respir Crit Care Med 181 A6853.

Gomi K, Arbelaez V, Crystal RG, and Walters MS (2015) Activation of NOTCH1 or NOTCH3 signaling skews human airway basal cell differentiation toward a secretory pathway. PLoS One 10:e0116507.

Gomi K, Staudt MR, Salit J, Kaner RJ, Heldrich J, Rogalski AM, Arbelaez V, Crystal RG, and Walters MS (2016) JAG1-mediated Notch signaling regulates secretory cell differentiation of the human airway epithelium. Stem Cell Rev 12 454-463.

Gong W, Wang X, Zhang Y, Hao J, Xing C, Chu Q, Wang G, Zhao J, Wang J, Dong Q, et al. (2014) Interleukin-20 promotes airway remodeling in asthma. Inflammation 37:2099-2105.

Gonzalez DM and Medici D (2014) Signaling mechanisms of the epithelialmesenchymal transition. Sci Signal 7:re8

Gordon WR, Vardar-Ulu D, L'Heureux S, Ashworth T, Malecki MJ, Sanchez-Irizarry C, McArthur DG, Histen G, Mitchell JL, Aster JC, et al. (2009) Effects of S1 cleavage on the structure, surface export, and signaling activity of human Notch1 and Notch2. PLoS One 4:e6613.

Greenwald I (1994) Structure/function studies of lin-12/Notch proteins. Curr Opin Genet Dev 4:556-562.

Gridley T (2007) Notch signaling in vascular development and physiology. Development 134:2709-2718.

Gridley T (2010) Notch signaling in the vasculature. Curr Top Dev Biol 92:277-309.

Gu W, Xu W, Ding T, and Guo X (2012) Fringe controls naïve CD4 $\left.{ }^{+}\right) \mathrm{T}$ cells differentiation through modulating notch signaling in asthmatic rat models. PLoS One 7:e47288

Guha A, Vasconcelos M, Zhao R, Gower AC, Rajagopal J, and Cardoso WV (2014) Analysis of Notch signaling-dependent gene expression in developing airways reveals diversity of Clara cells. PLoS One 9:e88848.

Guillemot F, Lo L-C, Johnson JE, Auerbach A, Anderson DJ, and Joyner AL (1993) Mammalian achaete-scute homolog 1 is required for the early development of olfactory and autonomic neurons. Cell 75:463-476.

Guo B, McMillan BJ, and Blacklow SC (2016) Structure and function of the Mind bomb E3 ligase in the context of Notch signal transduction. Curr Opin Struct Biol 41:38-45.

Guruharsha KG, Kankel MW, and Artavanis-Tsakonas S (2012) The Notch signalling system: recent insights into the complexity of a conserved pathway. Nat Rev Genet 13:654-666.

Guseh JS, Bores SA, Stanger BZ, Zhou Q, Anderson WJ, Melton DA, and Rajagopal J (2009) Notch signaling promotes airway mucous metaplasia and inhibits alveolar development. Development 136:1751-1759.

Hackett BP, Shimizu N, and Gitlin JD (1992) Clara cell secretory protein gene expression in bronchiolar epithelium. Am J Physiol 262:L399-L404.

Hamada Y, Kadokawa Y, Okabe M, Ikawa M, Coleman JR, and Tsujimoto Y (1999) Mutation in ankyrin repeats of the mouse Notch2 gene induces early embryonic lethality. Development 126:3415-3424.

Harkness LM, Ashton AW, and Burgess JK (2015) Asthma is not only an airway disease, but also a vascular disease. Pharmacol Ther 148:17-33.

Herreman A, Hartmann D, Annaert W, Saftig P, Craessaerts K, Serneels L, Umans L, Schrijvers V, Checler F, Vanderstichele H, et al. (1999) Presenilin 2 deficiency causes a mild pulmonary phenotype and no changes in amyloid precursor protein processing but enhances the embryonic lethal phenotype of presenilin 1 deficiency. Proc Natl Acad Sci USA 96:11872-11877.
Holderfield MT and Hughes CC (2008) Crosstalk between vascular endothelial growth factor, notch, and transforming growth factor- $\beta$ in vascular morphogenesis. Circ Res 102:637-652.

Hoyne GF, Le Roux I, Corsin-Jimenez M, Tan K, Dunne J, Forsyth LM, Dallman MJ, Owen MJ, Ish-Horowicz D, and Lamb JR (2000) Serrate1-induced notch signalling regulates the decision between immunity and tolerance made by peripheral CD4 $\left({ }^{+}\right)$ T cells. Int Immunol 12:177-185.

Hrabĕ de Angelis M, McIntyre J, II, and Gossler A (1997) Maintenance of somite borders in mice requires the Delta homologue DII1. Nature 386:717-721.

Hsu CK, Hsu CC, Lee JYY, Kuo YM, and Pai MC (2013) Exacerbation of psoriatic skin lesions in a patient with Alzheimer disease receiving gamma-secretase inhibitor. J Am Acad Dermatol 68:e46-e48.

Hu M, Ou-Yang H-F, Han X-P, Ti X-Y, and Wu C-G (2015) KyoT2 downregulates airway remodeling in asthma. Int J Clin Exp Pathol 8:14171-14179.

Hu M, Ou-Yang H-F, Wu C-G, Qu S-Y, Xu X-T, and Wang P (2014) Notch signaling regulates col $1 \alpha 1$ and $\operatorname{col} 1 \alpha 2$ expression in airway fibroblasts. Exp Biol Med (Maywood) 239:1589-1596.

Huang H-M, Hsiao G, Fan C-K, Lin C-L, Leu S-J, Chiang B-L, and Lee Y-L (2013) Notch ligand delta-like 4-pretreated dendritic cells alleviate allergic airway responses by enhancing IL-10 production. PLoS One 8:e63613.

Huang M-T, Chen Y-L, Lien C-I, Liu W-L, Hsu L-C, Yagita H, and Chiang B-L (2017) Notch ligand DLL4 alleviates allergic airway inflammation via induction of a homeostatic regulatory pathway. Sci Rep 7:43535.

Huang M-T, Dai Y-S, Chou Y-B, Juan Y-H, Wang C-C, and Chiang B-L (2009) Regulatory $\mathrm{T}$ cells negatively regulate neovasculature of airway remodeling via DLL4 Notch signaling. J Immunol 183:4745-4754.

Huber HL and Koessler KK (1922) The pathology of bronchial asthma. Arch Intern Med (Chic) 30:689-760.

Humbles AA, Lloyd CM, McMillan SJ, Friend DS, Xanthou G, McKenna EE, Ghiran S, Gerard NP, Yu C, Orkin SH, et al. (2004) A critical role for eosinophils in allergic airways remodeling. Science 305:1776-1779.

Ishibashi M, Ang S-L, Shiota K, Nakanishi S, Kageyama R, and Guillemot F (1995) Targeted disruption of mammalian hairy and Enhancer of split homolog-1 (HES-1) leads to up-regulation of neural helix-loop-helix factors, premature neurogenesis, and severe neural tube defects. Genes Dev 9:3136-3148.

Iso T, Hamamori Y, and Kedes L (2003) Notch signaling in vascular development. Arterioscler Thromb Vasc Biol 23:543-553.

Ito T, Udaka N, Yazawa T, Okudela K, Hayashi H, Sudo T, Guillemot F, Kageyama $\mathrm{R}$, and Kitamura H (2000) Basic helix-loop-helix transcription factors regulate the neuroendocrine differentiation of fetal mouse pulmonary epithelium. Development 127:3913-3921.

James AL, Elliot JG, Jones RL, Carroll ML, Mauad T, Bai TR, Abramson MJ, McKay $\mathrm{KO}$, and Green FH (2012) Airway smooth muscle hypertrophy and hyperplasia in asthma. Am J Respir Crit Care Med 185:1058-1064.

Jang S, Schaller M, Berlin AA, and Lukacs NW (2010) Notch ligand delta-like 4 regulates development and pathogenesis of allergic airway responses by modulating IL-2 production and Th2 immunity. J Immunol 185:5835-5844.

Jorissen E and De Strooper B (2010) $\gamma$-secretase and the intramembrane proteolysis of Notch. Curr Top Dev Biol 92:201-230.

Justice JP, Crosby J, Borchers MT, Tomkinson A, Lee JJ, and Lee NA (2002) CD4(+) T cell-dependent airway mucus production occurs in response to IL-5 expression in lung. Am J Physiol Lung Cell Mol Physiol 282:L1066-L1074.

Kaiko GE, Phipps S, Angkasekwinai P, Dong C, and Foster PS (2010) NK cell deficiency predisposes to viral-induced Th2-type allergic inflammation via epithelialderived IL-25. J Immunol 185:4681-4690.

Kalinichenko VV, Gusarova GA, Kim I-M, Shin B, Yoder HM, Clark J, Sapozhnikov AM, Whitsett JA, and Costa RH (2004) Foxf1 haploinsufficiency reduces Notch-2 signaling during mouse lung development. Am J Physiol Lung Cell Mol Physiol 286:L521-L530.

Kalinichenko VV, Lim L, Stolz DB, Shin B, Rausa FM, Clark J, Whitsett JA, Watkins SC, and Costa RH (2001) Defects in pulmonary vasculature and perinatal lung hemorrhage in mice heterozygous null for the Forkhead Box $\mathrm{fl}$ transcription factor. Dev Biol 235:489-506.

Kang JH, Kim BS, Uhm TG, Lee S-H, Lee GR, Park C-S, and Chung IY (2009) $\gamma$-secretase inhibitor reduces allergic pulmonary inflammation by modulating Th1 and Th2 responses. Am J Respir Crit Care Med 179:875-882.

Kang JH, Lee DH, Lee JS, Kim HJ, Shin JW, Lee YH, Lee YS, Park CS, and Chung IY (2005) Eosinophilic differentiation is promoted by blockage of Notch signaling with a gamma-secretase inhibitor. Eur J Immunol 35:2982-2990.

Kang JH, Lee DH, Seo H, Park JS, Nam KH, Shin SY, Park C-S, and Chung IY (2007) Regulation of functional phenotypes of cord blood derived eosinophils by $\gamma$-secretase inhibitor. Am J Respir Cell Mol Biol 37:571-577.

Kang JH, Lee EH, Park SW, and Chung IY (2011) MUC5AC expression through bidirectional communication of Notch and epidermal growth factor receptor pathways. J Immunol 187:222-229.

Kaufman GN, Massoud AH, Audusseau S, Banville-Langelier AA, Wang Y, Guay J, Garellek JA, Mourad W, Piccirillo CA, McCusker C, et al. (2011) Intravenous immunoglobulin attenuates airway hyperresponsiveness in a murine model of allergic asthma. Clin Exp Allergy 41:718-728.

Kavian N, Servettaz A, Weill B, and Batteux F (2012) New insights into the mechanism of notch signalling in fibrosis. Open Rheumatol $J$ 6:96-102.

Kay AB, Phipps S, and Robinson DS (2004) A role for eosinophils in airway remodelling in asthma. Trends Immunol 25:477-482.

Kearley J, Robinson DS, and Lloyd CM (2008) CD4+CD25+ regulatory T cells reverse established allergic airway inflammation and prevent airway remodeling. $J$ Allergy Clin Immunol 122:617-24.e6.

Kennard S, Liu H, and Lilly B (2008) Transforming growth factor- $\beta$ (TGF- 1) downregulates Notch3 in fibroblasts to promote smooth muscle gene expression. $J$ Biol Chem 283:1324-1333. 
Kii I, Nishiyama T, Li M, Matsumoto K, Saito M, Amizuka N, and Kudo A (2010) Incorporation of tenascin-C into the extracellular matrix by periostin underlies an extracellular meshwork architecture. J Biol Chem 285:2028-2039.

KleinJan A, de Bruijn M, van Nimwegen M, Bergen I, Hoogsteden HC, Amsen D, and Hendriks RW (2013) The notch mediator RBP-J in CD4 T cells plays a crucia role in the induction of allergic asthma in mice. $J$ Allergy Clin Immunol 131: $\mathrm{AB} 147$

Kong Y, Glickman J, Subramaniam M, Shahsafaei A, Allamneni KP, Aster JC, Sklar J, and Sunday ME (2004) Functional diversity of notch family genes in fetal lung development. Am J Physiol Lung Cell Mol Physiol 286:L1075-L1083.

Koo B-K, Yoon M-J, Yoon K-J, Im S-K, Kim Y-Y, Kim C-H, Suh P-G, Jan YN, and Kong Y-Y (2007) An obligatory role of mind bomb-1 in notch signaling of mammalian development. PLoS One 2:e1221.

Kopan R and Ilagan MXG (2009) The canonical Notch signaling pathway: unfolding the activation mechanism. Cell 137:216-233.

Kovall RA, Gebelein B, Sprinzak D, and Kopan R (2017) The canonical Notch signaling pathway: structural and biochemical insights into shape, sugar, and force. Dev Cell 41:228-241.

Krebs LT, Xue Y, Norton CR, Shutter JR, Maguire M, Sundberg JP, Gallahan D, Closson V, Kitajewski J, Callahan R, et al. (2000) Notch signaling is essential for vascular morphogenesis in mice. Genes Dev 14:1343-1352.

Kurooka H and Honjo T (2000) Functional interaction between the mouse notch1 intracellular region and histone acetyltransferases PCAF and GCN5. J Biol Chem 275:17211-17220.

Lafkas D, Shelton A, Chiu C, de Leon Boenig G, Chen Y, Stawicki SS, Siltanen C, Reichelt M, Zhou M, Wu X, et al. (2015) Therapeutic antibodies reveal Notch control of transdifferentiation in the adult lung. Nature 528:127-131.

Lan Q, Chen H, Xu B, Zhang W, Zheng S, Shi W, and Xu W (2012) Adoptive transfer of induced-regulatory $\mathrm{T}$ cells effectively attenuates murine airway allergic inflammation. Am J Respir Crit Care Med 185:A4305.

Lee TV, Sethi MK, Leonardi J, Rana NA, Buettner FF, Haltiwanger RS, Bakker H, and Jafar-Nejad H (2013) Negative regulation of notch signaling by xylose. PLoS Genet 9:e1003547.

Leimeister C, Schumacher N, Steidl C, and Gessler M (2000) Analysis of HeyL expression in wild-type and Notch pathway mutant mouse embryos. Mech Dev 98: 175-178.

Leong KG, Niessen K, Kulic I, Raouf A, Eaves C, Pollet I, and Karsan A (2007) Jagged1-mediated Notch activation induces epithelial-to-mesenchymal transition through Slug-induced repression of E-cadherin. J Exp Med 204:2935-2948.

Li W, Gao P, Zhi Y, Xu W, Wu Y, Yin J, and Zhang J (2015) Periostin: its role in asthma and its potential as a diagnostic or therapeutic target. Respir Res 16:57.

Li X, Zhang X, Leathers R, Makino A, Huang C, Parsa P, Macias J, Yuan JX, Jamieson SW, and Thistlethwaite PA (2009) Notch3 signaling promotes the development of pulmonary arterial hypertension. Nat Med 15:1289-1297.

Liu LY, Wang H, Xenakis JJ, and Spencer LA (2015) Notch signaling mediates granulocyte-macrophage colony-stimulating factor priming-induced transendothelial migration of human eosinophils. Allergy 70:805-812.

Liu T, Hu B, Choi YY, Chung M, Ullenbruch M, Yu H, Lowe JB, and Phan SH (2009) Notch1 signaling in FIZZ1 induction of myofibroblast differentiation. Am J Pathol 174:1745-1755.

Liu Z-J, Li Y, Tan Y, Xiao M, Zhang J, Radtke F, and Velazquez OC (2012) Inhibition of fibroblast growth by Notch1 signaling is mediated by induction of Wnt11 dependent WISP-1. PLoS One 7:e38811.

Loffredo LF, Abdala-Valencia H, Anekalla KR, Cuervo-Pardo L, Gottardi CJ, and Berdnikovs S (2017) Beyond epithelial-to-mesenchymal transition: common suppression of differentiation programs underlies epithelial barrier dysfunction in mild, moderate, and severe asthma. Allergy Jun 9:1-17. DOI: 10.1111/all.13222 (published ahead of print).

Logeat F, Bessia C, Brou C, LeBail O, Jarriault S, Seidah NG, and Israël A (1998) The Notch1 receptor is cleaved constitutively by a furin-like convertase. Proc Nat Acad Sci USA 95:8108-8112.

Malecki MJ, Sanchez-Irizarry C, Mitchell JL, Histen G, Xu ML, Aster JC, and Blacklow SC (2006) Leukemia-associated mutations within the NOTCH1 heterodimerization domain fall into at least two distinct mechanistic classes. $\mathrm{Mol}$ Cell Biol 26:4642-4651.

Mašek J and Andersson ER (2017) The developmental biology of genetic Notch disorders. Development 144:1743-1763.

Mathern DR, Laitman LE, Hovhannisyan Z, Dunkin D, Farsio S, Malik TJ, Roda G, Chitre A, Iuga AC, Yeretssian G, et al. (2014) Mouse and human Notch-1 regulate mucosal immune responses. Mucosal Immunol 7:995-1005.

Matsuno Y, Coelho AL, Jarai G, Westwick J, and Hogaboam CM (2012) Notch signaling mediates TGF- $\beta 1$-induced epithelial-mesenchymal transition through the induction of Snai1. Int J Biochem Cell Biol 44:776-789.

McCright B (2003) Notch signaling in kidney development. Curr Opin Nephrol Hypertens 12:5-10.

Metzger RJ, Klein OD, Martin GR, and Krasnow MA (2008) The branching programme of mouse lung development. Nature 453:745-750.

Miniati D, Jelin EB, Ng J, Wu J, Carlson TR, Wu X, Looney MR, and Wang RA (2010) Constitutively active endothelial Notch4 causes lung arteriovenous shunts in mice. Am J Physiol Lung Cell Mol Physiol 298:L169-L177.

Monick MM, Powers LS, Hassan I, Groskreutz D, Yarovinsky TO, Barrett CW, Castilow EM, Tifrea D, Varga SM, and Hunninghake GW (2007) Respiratory syncytial virus synergizes with Th2 cytokines to induce optimal levels of TARC/ CCL17. J Immunol 179:1648-1658.

Morgan TH (1917) The theory of the gene. Am Nat 51:513-544

Mori M, Mahoney JE, Stupnikov MR, Paez-Cortez JR, Szymaniak AD, Varelas X Herrick DB, Schwob J, Zhang H, and Cardoso WV (2015) Notch3-Jagged signaling controls the pool of undifferentiated airway progenitors. Development 142:258-267. Morimoto M, Liu Z, Cheng H-T, Winters N, Bader D, and Kopan R (2010) Canonical Notch signaling in the developing lung is required for determination of arterial smooth muscle cells and selection of Clara versus ciliated cell fate. J Cell Sci $\mathbf{1 2 3}$ 213-224.

Morimoto M, Nishinakamura R, Saga Y, and Kopan R (2012) Different assemblies of Notch receptors coordinate the distribution of the major bronchial Clara, ciliated and neuroendocrine cells. Development 139:4365-4373.

Morrisey EE and Hogan BL (2010) Preparing for the first breath: genetic and cellular mechanisms in lung development. Dev Cell 18:8-23.

Mukherjee S, Rasky AJ, Lundy PA, Kittan NA, Kunkel SL, Maillard IP, Kowalski PE, Kousis PC, Guidos CJ, and Lukacs NW (2014) STAT5-induced lunatic fringe during Th2 development alters delta-like 4-mediated Th2 cytokine production in respiratory syncytial virus-exacerbated airway allergic disease. J Immunol 192: 996-1003.

Nagira T, Nagahata-Ishiguro M, and Tsuchiya T (2007) Effects of sulfated hyaluronan on keratinocyte differentiation and Wnt and Notch gene expression. Biomaterials 28:844-850.

Nakahara H, Gabazza EC, Fujimoto H, Nishii Y, D'Alessandro-Gabazza CN, Bruno NE, Takagi T, Hayashi T, Maruyama J, Maruyama K, et al. (2006) Deficiency of tenascin $\mathrm{C}$ attenuates allergen-induced bronchial asthma in the mouse. Eur $J$ Immunol 36:3334-3345.

Nam Y, Sliz P, Song L, Aster JC, and Blacklow SC (2006) Structural basis for cooperativity in recruitment of MAML coactivators to Notch transcription complexes. Cell 124:973-983.

Niwa Y, Masamizu Y, Liu T, Nakayama R, Deng C-X, and Kageyama R (2007) The initiation and propagation of Hes7 oscillation are cooperatively regulated by Fgf and notch signaling in the somite segmentation clock. Dev Cell 13:298-304.

Noguchi M, Sumiyama K, and Morimoto M (2015) Directed migration of pulmonary neuroendocrine cells toward airway branches organizes the stereotypic location of neuroepithelial bodies. Cell Reports 13:2679-2686.

Norris RA, Damon B, Mironov V, Kasyanov V, Ramamurthi A, Moreno-Rodriguez R, Trusk T, Potts JD, Goodwin RL, Davis J, et al. (2007) Periostin regulates collagen fibrillogenesis and the biomechanical properties of connective tissues. J Cell Biochem 101:695-711.

Noseda M, Fu Y, Niessen K, Wong F, Chang L, McLean G, and Karsan A (2006) Smooth muscle $\alpha$-actin is a direct target of Notch/CSL. Circ Res 98:1468-1470.

Okajima T, Xu A, and Irvine KD (2003) Modulation of notch-ligand binding by protein O-fucosyltransferase 1 and fringe. $J$ Biol Chem 278:42340-42345.

Okamoto M, Matsuda H, Joetham A, Lucas JJ, Domenico J, Yasutomo K, Takeda K, and Gelfand EW (2009) Jagged1 on dendritic cells and Notch on CD4 ${ }^{+} \mathrm{T}$ cells initiate lung allergic responsiveness by inducing IL-4 production. J Immunol 183: 2995-3003.

Ong C-T, Cheng H-T, Chang L-W, Ohtsuka T, Kageyama R, Stormo GD, and Kopan R (2006) Target selectivity of vertebrate notch proteins. Collaboration between disrete domains and CSL-binding site architecture determines activation probability. $J$ Biol Chem 281:5106-5119.

Ono Y, Sensui H, Okutsu S, and Nagatomi R (2007) Notch2 negatively regulates myofibroblastic differentiation of myoblasts. J Cell Physiol 210:358-369.

Ostroukhova M, Qi Z, Oriss TB, Dixon-McCarthy B, Ray P, and Ray A (2006) Tregmediated immunosuppression involves activation of the Notch-HES1 axis by membrane-bound TGF- $\beta$. J Clin Invest 116:996-1004

Oswald F, Winkler M, Cao Y, Astrahantseff K, Bourteele S, Knöchel W, and Borggrefe T (2005) RBP-Jkappa/SHARP recruits CtIP/CtBP corepressors to silence Notch target genes. Mol Cell Biol 25:10379-10390.

Ou-Yang H-F, Wu C-G, Qu S-Y, and Li Z-K (2013) Notch signaling downregulates MUC5AC expression in airway epithelial cells through Hes1-dependent mechanisms. Respiration 86:341-346.

Pardo-Saganta A, Tata PR, Law BM, Saez B, Chow RD-W, Prabhu M, Gridley T, and Rajagopal J (2015) Parent stem cells can serve as niches for their daughter cells. Nature 523:597-601.

Pascual RM and Peters SP (2005) Airway remodeling contributes to the progressive loss of lung function in asthma: an overview. J Allergy Clin Immunol 116:477-486, quiz 487.

Post LC, Ternet M, and Hogan BL (2000) Notch/Delta expression in the developing mouse lung. Mech Dev 98:95-98.

Prakash YS (2013) Airway smooth muscle in airway reactivity and remodeling: what have we learned? Am J Physiol Lung Cell Mol Physiol 305:L912-L933.

Purow B (2012) Notch inhibition as a promising new approach to cancer therapy, in Notch Signaling in Embryology and Cancer, pp. 305-319, Springer, New York.

Radke AL, Reynolds LE, Melo RC, Dvorak AM, Weller PF, and Spencer LA (2009) Mature human eosinophils express functional Notch ligands mediating eosinophi autocrine regulation. Blood 113:3092-3101.

Radtke F and Raj K (2003) The role of Notch in tumorigenesis: oncogene or tumour suppressor? Nat Rev Cancer 3:756-767.

Ramain P, Khechumian K, Seugnet L, Arbogast N, Ackermann C, and Heitzler P (2001) Novel Notch alleles reveal a Deltex-dependent pathway repressing neural fate. Curr Biol 11:1729-1738.

Rana NA and Haltiwanger RS (2011) Fringe benefits: functional and structural impacts of O-glycosylation on the extracellular domain of Notch receptors. Curr Opin Struct Biol 21:583-589.

Ranganathan P, Weaver KL, and Capobianco AJ (2011) Notch signalling in solid tumours: a little bit of everything but not all the time. Nat Rev Cancer 11:338-351.

Rawlins EL and Hogan BL (2006) Epithelial stem cells of the lung: privileged few or opportunities for many? Development 133:2455-2465.

Rawlins EL, Okubo T, Xue Y, Brass DM, Auten RL, Hasegawa H, Wang F, and Hogan BL (2009) The role of Scgb1a1 + Clara cells in the long-term maintenance and repair of lung airway, but not alveolar, epithelium. Cell Stem Cell $\mathbf{4}$ 525-534.

Raya A, Kawakami Y, Rodríguez-Esteban C, Ibañes M, Rasskin-Gutman D, Rodríguez-León J, Büscher D, Feijó JA, and Izpisúa Belmonte JC (2004) Notch activity acts as a sensor for extracellular calcium during vertebrate left-right determination. Nature 427:121-128. 
Real PJ, Tosello V, Palomero T, Castillo M, Hernando E, de Stanchina E, Sulis ML, Barnes K, Sawai C, Homminga I, et al. (2009) $\gamma$-secretase inhibitors reverse glucocorticoid resistance in T cell acute lymphoblastic leukemia. Nat Med 15:50-58.

Roca C and Adams RH (2007) Regulation of vascular morphogenesis by Notch signaling. Genes Dev 21:2511-2524.

Rock JR, Gao X, Xue Y, Randell SH, Kong Y-Y, and Hogan BL (2011) Notchdependent differentiation of adult airway basal stem cells. Cell Stem Cell 8: $639-648$.

Rock JR, Onaitis MW, Rawlins EL, Lu Y, Clark CP, Xue Y, Randell SH, and Hogan BL (2009) Basal cells as stem cells of the mouse trachea and human airway epithelium. Proc Natl Acad Sci USA 106:12771-12775.

Rogers NK, Clements D, Harrison TW, Shaw D, and Johnson SR (2012) S11 expression of tenascin-C regulates airway smooth muscle derived matrix metalloproteinase-1 in asthma. Thorax 67:A8.2-A8

Sarkar S, Mirzaei R, Zemp FJ, Wei W, Senger DL, Robbins SM, and Yong VW (2017) Activation of NOTCH signaling by tenascin-C promotes growth of human brain tumor-initiating cells. Cancer Res 77:3231-3243.

Saura CA (2010) Presenilin/ $\gamma$-secretase and inflammation. Front Aging Neurosci 2 16.

Schaller MA, Neupane R, Rudd BD, Kunkel SL, Kallal LE, Lincoln P, Lowe JB, Man Y, and Lukacs NW (2007) Notch ligand Delta-like 4 regulates disease pathogenesis during respiratory viral infections by modulating Th2 cytokines. J Exp Med 204: $2925-2934$

Schittny JC (2017) Development of the lung. Cell Tissue Res 367:427-444

Shan L, Aster JC, Sklar J, and Sunday ME (2007) Notch-1 regulates pulmonary neuroendocrine cell differentiation in cell lines and in transgenic mice. Am J Physiol Lung Cell Mol Physiol 292:L500-L509.

Shi YH, Shi GC, Wan HY, Jiang LH, Ai XY, Zhu HX, Tang W, Ma JY, Jin XY, and Zhang BY (2011) Coexistence of Th1/Th2 and Th17/Treg imbalances in patients with allergic asthma. Chin Med $J$ (Engl) 124:1951-1956.

Shifren A, Witt C, Christie C, and Castro M (2012) Mechanisms of remodeling in asthmatic airways. J Allergy (Cairo) 2012:316049.

Siekmann AF, Covassin L, and Lawson ND (2008) Modulation of VEGF signalling output by the Notch pathway. BioEssays 30:303-313.

Sivasankaran B, Degen M, Ghaffari A, Hegi ME, Hamou MF, Ionescu MCS, Zweifel C, Tolnay M, Wasner M, Mergenthaler S, et al. (2009) Tenascin-C is a novel RBPJkappa-induced target gene for Notch signaling in gliomas. Cancer Res 69 $458-465$

Song Y, Zhang Y, Jiang H, Zhu Y, Liu L, Feng W, Yang L, Wang Y, and Li M (2015) Activation of Notch3 promotes pulmonary arterial smooth muscle cells proliferation via Hes1/p27Kip1 signaling pathway. FEBS Open Bio 5:656-660.

Sriuranpong V, Borges MW, Strock CL, Nakakura EK, Watkins DN, Blaumueller CM, Nelkin BD, and Ball DW (2002) Notch signaling induces rapid degradation of achaete-scute homolog 1. Mol Cell Biol 22:3129-3139.

Steidl C, Leimeister C, Klamt B, Maier M, Nanda I, Dixon M, Clarke R, Schmid M, and Gessler M (2000) Characterization of the human and mouse HEY1, HEY2, and HEYL genes: cloning, mapping, and mutation screening of a new bHLH gene family. Genomics 66:195-203.

Swiatek PJ, Lindsell CE, del Amo FF, Weinmaster G, and Gridley T (1994) Notch1 is essential for postimplantation development in mice. Genes Dev 8:707-719.

Tadokoro T, Wang Y, Barak LS, Bai Y, Randell SH, and Hogan BL (2014) IL-6/STAT3 promotes regeneration of airway ciliated cells from basal stem cells. Proc Natl Acad Sci USA 111:E3641-E3649.

Taichman DB, Loomes KM, Schachtner SK, Guttentag S, Vu C, Williams P, Oakey RJ, and Baldwin HS (2002) Notch1 and Jagged1 expression by the developing pulmonary vasculature. Dev Dyn 225:166-175.

Takebe N, Nguyen D, and Yang SX (2014) Targeting notch signaling pathway in cancer: clinical development advances and challenges. Pharmacol Ther 141: 140-149.

Tanigaki K, Tsuji M, Yamamoto N, Han H, Tsukada J, Inoue H, Kubo M, and Honjo T (2004) Regulation of alphabeta/gammadelta $\mathrm{T}$ cell lineage commitment and peripheral T cell responses by Notch/RBP-J signaling. Immunity 20:611-622.

Tindemans I, Lukkes M, de Bruijn MJ, Li BW, van Nimwegen M, Amsen D, KleinJan A, and Hendriks RW (2017) Notch signaling in T cells is essential for allergic airway inflammation, but expression of Notch ligands Jagged1 and Jagged2 on dendritic cells is dispensable. J Allergy Clin Immunol 140:1079-1089.

Ting H-A, Schaller MA, de Almeida Nagata DE, Rasky AJ, Maillard IP, and Lukacs NW (2017) Notch ligand Delta-like 4 promotes regulatory T cell identity in pulmonary viral infection. J Immunol 198:1492-1502.

Tompkins DH, Besnard V, Lange AW, Wert SE, Keiser AR, Smith AN, Lang R, and Whitsett JA (2009) Sox2 is required for maintenance and differentiation of bronchiolar Clara, ciliated, and goblet cells. PLoS One 4:e8248.

Tsai T-H, Sun M-H, Ho T-C, Ma H-I, Liu M-Y, and Tsao Y-P (2014) Notch prevents transforming growth factor-beta-assisted epithelial-mesenchymal transition in cultured limbal progenitor cells through the induction of Smad7. Mol Vis 20: 522-534.

Tsao P-N, Chen F, Izvolsky KI, Walker J, Kukuruzinska MA, Lu J, and Cardoso WV (2008) $\gamma$-secretase activation of notch signaling regulates the balance of proximal and distal fates in progenitor cells of the developing lung. $J$ Biol Chem 283 29532-29544.

Tsao P-N, Matsuoka C, Wei S-C, Sato A, Sato S, Hasegawa K, Chen HK, Ling T-Y, Mori M, Cardoso WV, et al. (2016) Epithelial Notch signaling regulates lung alveolar morphogenesis and airway epithelial integrity. Proc Natl Acad Sci USA 113 : 8242-8247.
Tsao P-N, Vasconcelos M, Izvolsky KI, Qian J, Lu J, and Cardoso WV (2009) Notch signaling controls the balance of ciliated and secretory cell fates in developing airways. Development 136:2297-2307.

Tsao P-N, Wei S-C, Wu M-F, Huang M-T, Lin H-Y, Lee M-C, Lin KM-C, Wang I-J, Kaartinen V, Yang L-T, et al. (2011) Notch signaling prevents mucous metaplasia in mouse conducting airways during postnatal development. Development 138: 3533-3543.

van Es JH, van Gijn ME, Riccio O, van den Born M, Vooijs M, Begthel H, Cozijnsen M, Robine S, Winton DJ, Radtke F, et al. (2005) Notch/gamma-secretase inhibition turns proliferative cells in intestinal crypts and adenomas into goblet cells. Nature 435:959-963.

van Tuyl M, Groenman F, Kuliszewski M, Ridsdale R, Wang J, Tibboel D, and Post $\mathrm{M}$ (2005) Overexpression of lunatic fringe does not affect epithelial cell differentiation in the developing mouse lung. Am J Physiol Lung Cell Mol Physiol 288: L672-L682.

Venge $\mathrm{P}(2010)$ The eosinophil and airway remodelling in asthma. Clin Respir $J \mathbf{4}$ (Suppl 1):15-19.

Wakabayashi N, Chartoumpekis DV, and Kensler TW (2015) Crosstalk between Nrf2 and Notch signaling. Free Radic Biol Med 88 (Pt B):158-167.

Wallberg AE, Pedersen K, Lendahl U, and Roeder RG (2002) p300 and PCAF act cooperatively to mediate transcriptional activation from chromatin templates by notch intracellular domains in vitro. Mol Cell Biol 22:7812-7819.

Warburton D, El-Hashash A, Carraro G, Tiozzo C, Sala F, Rogers O, De Langhe S, Kemp PJ, Riccardi D, Torday J, et al. (2010) Lung organogenesis. Curr Top Dev Biol 90:73-158.

Weinmaster G and Fischer JA (2011) Notch ligand ubiquitylation: what is it good for? Dev Cell 21:134-144

Wong GT, Manfra D, Poulet FM, Zhang Q, Josien H, Bara T, Engstrom L, PinzonOrtiz M, Fine JS, Lee HJJ, et al. (2004) Chronic treatment with the $\gamma$-secretase inhibitor LY-411,575 inhibits $\beta$-amyloid peptide production and alters lymphopoiesis and intestinal cell differentiation. J Biol Chem 279:12876-12882.

Xie M, Zhang L, He CS, Xu F, Liu JL, Hu ZH, Zhao LP, and Tian Y (2012) Activation of Notch-1 enhances epithelial-mesenchymal transition in gefitinib-acquired resistant lung cancer cells. J Cell Biochem 113:1501-1513.

Xing Y, Li C, Li A, Sridurongrit S, Tiozzo C, Bellusci S, Borok Z, Kaartinen V, and Minoo P (2010) Signaling via Alk5 controls the ontogeny of lung Clara cells. Development 137:825-833.

Xu K, Nieuwenhuis E, Cohen BL, Wang W, Canty AJ, Danska JS, Coultas L, Rossant J, Wu MY, Piscione TD, et al. (2010) Lunatic Fringe-mediated Notch signaling is required for lung alveogenesis. Am J Physiol Lung Cell Mol Physiol 298:L45-L56. Xu W, Lan Q, Chen M, Chen H, Zhu N, Zhou X, Wang J, Fan H, Yan C-S, Kuang J-L, et al. (2012) Adoptive transfer of induced-Treg cells effectively attenuates murine airway allergic inflammation. PLoS One 7:e40314.

Xue Y, Gao X, Lindsell CE, Norton CR, Chang B, Hicks C, Gendron-Maguire M, Rand EB, Weinmaster G, and Gridley T (1999) Embryonic lethality and vascular defects in mice lacking the Notch ligand Jagged1. Hum Mol Genet 8:723-730.

Yamamoto S, Charng W-L, and Bellen HJ (2010) Endocytosis and intracellular trafficking of Notch and its ligands. Curr Top Dev Biol 92:165-200.

Yoneya T, Tahara T, Nagao K, Yamada Y, Yamamoto T, Osawa M, Miyatani S, and Nishikawa M (2001) Molecular cloning of delta-4, a new mouse and human Notch ligand. J Biochem 129:27-34.

Yoshiura S, Ohtsuka T, Takenaka Y, Nagahara H, Yoshikawa K, and Kageyama R (2007) Ultradian oscillations of Stat, Smad, and Hes1 expression in response to serum. Proc Natl Acad Sci USA 104:11292-11297.

Zavadil J, Cermak L, Soto-Nieves N, and Böttinger EP (2004) Integration of TGF$\beta /$ Smad and Jagged1/Notch signalling in epithelial-to-mesenchymal transition. EMBO J 23:1155-1165.

Zhang HP, Fu JJ, Fan T, Zhang WB, Wang ZL, Wang L, and Wang G (2015b) Histone deacetylation of memory $\mathrm{T}$ lymphocytes by You-Gui-Wan alleviates allergeninduced eosinophilic airway inflammation in asthma. Chin Med 10:9.

Zhang S, Loch AJ, Radtke F, Egan SE, and Xu K (2013a) Jagged1 is the major regulator of Notch-dependent cell fate in proximal airways. Dev Dyn 242:678-686. Zhang W, Nie Y, Chong L, Cai X, Zhang H, Lin B, Liang Y, and Li C (2013b) PI3K and Notch signal pathways coordinately regulate the activation and proliferation of T lymphocytes in asthma. Life Sci 92:890-895.

Zhang W, Zhang X, Sheng A, Weng C, Zhu T, Zhao W, and Li C (2015a) $\gamma$-Secretase inhibitor alleviates acute airway inflammation of allergic asthma in mice by downregulating Th17 cell differentiation. Mediators Inflamm 2015:258168.

Zheng GY (2016) Cornuside ameliorates airway inflammation via Toll-like receptor 4 and Notch1 in asthmatic mice induced by lipopolysaccharide and ovalbumin. Int $J$ Clin Exp Med 9:15274-15284.

Zhou M, Cui ZL, Guo XJ, Ren LP, Yang M, Fan ZW, Han RC, and Xu WG (2015) Blockade of Notch signalling by $\gamma$-secretase inhibitor in lung $\mathrm{T}$ cells of asthmatic mice affects $\mathrm{T}$ cell differentiation and pulmonary inflammation. Inflammation 38 : 1281-1288.

Zhou S, Fujimuro M, Hsieh JJ-D, Chen L, Miyamoto A, Weinmaster G, and Hayward SD (2000) SKIP, a CBF1-associated protein, interacts with the ankyrin repeat domain of NotchIC To facilitate NotchIC function. Mol Cell Biol 20:2400-2410.

Address correspondence to: Dr. Ximei Wu, Department of Pharmacology, School of Medicine, Zhejiang University, 866 Yuhangtang Rd., Hangzhou, 310058, China. E-mail: xiwu@zju.edu.cn 